\title{
The Contribution of US Bond Demand to the US Bond Yield Conundrum of 2004 to 2007: An Empirical Investigation
}

\author{
Thomas Goda \\ School of Economics and Finance, Universidad EAFIT \\ Photis Lysandrou \\ Londom Mtropolitan Business School, London Metropolitan University \\ Chris Stewart \\ School of Economics, History and Politics, Kingston University
}

\begin{abstract}
Although the federal funds rate started rising from mid-2004 US long term rates continued to fall. A likely contributory factor to this 'conundrum' was the contemporaneous increase in US bond demand. Using ARDL based models, which accommodate structural breaks, this paper estimates the impact of foreign and domestic demand on AAA rated US bond yields in the 'conundrum' period. This impact is shown to have been everywhere significantly negative. The fact that our model fully explains the 'bond yield conundrum' gives support to the hypothesis that the US CDO market was rapidly expanded before 2007 chiefly to absorb the overspill of global demand for safe assets. Moreover, our models demonstrate that there are strong linkages between the 10-year Treasury yield and the long term yields of AAA rated non-Treasury bonds.
\end{abstract}

Key Words: ARDL modeling; bond yield conundrum; investor demand; subprime crisis; structural breaks

JEL Classification: C22; G01; G12; E43 


\section{Introduction}

From 2002 to mid-2007 when the US subprime crisis broke out US bond yields were at unusually low levels. Before mid-2004 these levels could be explained by the greater stability of 'fundamentals' and low short term interest rates (the 'great moderation'), but the persistence of these low yields after that point in time was puzzling. Financial markets expected long term rates to rise in tandem with the rise in the federal funds rate as was the case in previous periods of monetary tightening. This did not happen. On the contrary, not only did long term rates not rise they actually continued to fall ${ }^{1}$ (see Figure 1). As Alan Greenspan, the then Chairman of the Federal Reserve, stated before Congress in June 2005: "Among the biggest surprises of the past year has been the pronounced decline in long term interest rates on U.S. Treasury securities despite a 2-percentage-point increase in the federal funds rate. This is clearly without recent precedent. ... Moreover, even after the recent backup in credit risk spreads, yields for ... corporate bonds have declined even more than Treasuries over the same period." (Greenspan, 2005, p.1).

\section{[Insert Figure 1 here]}

What caused this 'bond yield conundrum'? Considering that its appearance coincided with a marked upswing in investor demand for US bonds (see Figure 2) it is possible that a considerable part of the downward pressure on US bond yields stemmed from that demand (Bernanke et al., 2011). To verify this possibility, a number of empirical studies have focused specifically on the impact of foreign government demand for US Treasuries on long term Treasury yields. Foreign official investor demand began to increase after February 1994 when China devalued its

\footnotetext{
${ }^{1}$ In June 2005 the long term rate was 73 basis points lower than it was one year before. In December 2006 the rate was still slightly lower, although the federal funds rate was 425 basis points higher than it was $2 \frac{1}{2}$ years earlier and expected to stay relatively stable above the 4\% level until 2015 (Kozicki and Sellon, 2005).
} 
currency, but the rate of increase in that demand accelerated even more sharply after 2003 as many emerging market economy governments sought to preserve part of their increasing commodity revenues and export surpluses in safe stores of value. While some studies found no evidence of a long term demand impact on Treasury yields (e.g. ECB, 2006; Rudebusch et al., 2006), the majority of recent studies have found evidence of a negative impact, albeit that the estimated size of the impact varied from study to study (e.g. Idier et al., 2007; Bandholz et al., 2009; Craine and Martin, 2009; Warnock and Cacdac Warnock, 2009, Bertaut et al., 2011).

\section{[Insert Figure 2 here]}

In this paper we assess the impact of investor demand on long term Treasury yields using an autoregressive distributed lag (ARDL) based econometric model. Since it has become well established that the increase in demand for US bonds stemmed not only from foreign official investors but also from private foreign (mainly European) and domestic investors (Bernanke et al., 2011) we consider the impact of all of these sources of demands on yields. Further, given that the 'bond yield conundrum' applied as much to the other major US bond markets as to the Treasury market, one would have expected an analysis of the impact of demand on long term yields in these other markets. As there has been no such analysis ${ }^{2}$, this paper seeks to fill this lacuna by modeling the impact of foreign and domestic investor demand on US agency, and AAA rated corporate and municipal bond yields using ARDL-based models. As an additional

\footnotetext{
2 To our knowledge nearly all existing studies on the 'conundrum' concentrate on the demand from foreign official sources on long term Treasury yields. Exceptions in this regard, which are however not all-encompassing as this study, are: ECB (2006) who test the impact of foreign official purchases on corporate bond yields and agency bond yields (without presenting their models in detail), Xiao and Xiao (2009) who test for the impact of pension funds on the yields of Treasuries and investment grade corporate bonds (without accounting for the demand from foreign sources and other domestic private investors), Warnock and Cacdac Warnock (2009) who test if the increase in Treasury purchases from foreign sources had a negative effect on the yield of corporate bonds and mortgage rates (without accounting for the demand for non-Treasury bonds), and Bertaut et al. (2011) who estimate the spillover impacts of foreign official purchases of Treasuries and Agency bonds on the 30-year fixed mortgage rate, Fanny Mae MBS yields and AAA rated corporate yield, and the impact of foreign purchases of corporate bonds on the AAA rated corporate bond yield (without accounting for private domestic demand).
} 
novelty we also consider whether there are linkages between the 10-year Treasury bond yield and the long term yields of AAA rated non-Treasury bonds.

In our view, an important by-product of this econometric assessment of the contribution of demand to the US 'bond yield conundrum' is that it may help to resolve the question as to why the US collateralized debt obligation (CDO) market was allowed to grow in a very short time to a size that was able to trigger widespread financial panic when this market suddenly collapsed in August $2007^{3}$. The conventional answer to this question is one that places the major burden of responsibility on the US financial system itself. However, there is a minority view that, while the US banks and their associates cannot be absolved from blame in accelerating the rate of production of CDOs right up to mid-2007, the major driving force behind that acceleration was the pressure of demand for US safe assets spilling over from other major US debt security markets (e.g. Caballero and Krishnamurthy, 2009; Gros, 2009; Lysandrou, 2009; Caballero, 2010). Clearly, this alternative view, and its ensuing policy implications, would command far more attention were it to be convincingly demonstrated that the rise in foreign and domestic demand for US bonds in the period leading up to the outbreak of the subprime crisis did indeed have a substantial significant negative impact on all highly rated traditional fixed income products.

The layout of this paper is as follows. Section two gives details of the model specification, the data used and the chosen sample period. Section three presents and discusses the estimation results while section four briefly comments on their policy implications. Section five concludes.

\footnotetext{
3 For a good overview about the properties of CDOs and the reason why the breakdown of this market triggered the financial crisis see Dwyer and Tkac (2009).
} 


\section{Model specification and model selection}

\subsection{Rationale for the models}

Any attempt to quantify the impact of demand on bond yields has to begin with a specification of all of the major determinants of yields. According to recent research (see e.g. Rudebusch et al., 2006; Wu, 2008) these determinants broadly divide into two groups, those relating to macroeconomic essentials on the one hand and those relating to financial risk on the other. Apart from the short term interest rate, which is usually expected to influence nominal long term yields, inflation and the business cycle are also believed to be important determinants of these yields (see e.g. Rudebusch and Wu, 2008; Bandholz et al., 2009; Warnock and Cacdac Warnock, 2009).

Changes in actual inflation can influence expectations about the real value of future coupon payments, the future federal funds rate and long term inflation rates, while changes in long term inflation expectations influence expectations about future short term interest rates and the real par value at maturity. Growth expectations possibly influence long term interest rates because in a boom market participants often expect inflationary pressure and a rise in the federal funds rate to prevent an overheating of the economy and thus request higher yields, and vice versa. As stated, beyond these macroeconomic indicators changes in default risk and volatility can also influence the long term yield (see e.g. Rudebusch et al., 2006). A decrease in the volatility of bond yields, for example, decreases the risk for market participants and thus is expected to lower the yield.

The inclusion of bond demand as a possible determinant of bond yields is not uncontroversial. Investor demand should have no impact on yields in a world where financial markets are frictionless and all assets classes are perfect substitutes (ECB, 2006). However, we shall consider the alternative position that financial markets are not frictionless and that bonds have certain 
distinct properties that enable them to meet investors' needs in ways that other asset classes cannot (for a clear exposition of bond characteristics and their attraction for investors see e.g. Krishnamurthy and Vissing-Jorgensen, 2007; Greenwood and Vayanos, 2010) ${ }^{4}$. In sum, our basic model can be represented by the following equation:

$$
y^{l}=f\left(i^{s}, \pi, \pi^{e}, g^{e}, r p, d\right)
$$

where $y^{l}$ denotes the long term interest rate, $i^{s}$ the short term interest rate, $\pi$ current inflation, $\pi^{e}$ inflation expectations, $g^{e}$ growth expectations and $r p$ is a risk premium for the expected default risk and macroeconomic and financial volatility, while $d$ denotes investor demand for bonds (in the case of the non-Treasury yields the impact of the Treasury yield is additionally taken into account as it is often seen as a reference for other yields). Since we consider more than one proxy for each explanatory factor there are up to 16 variables to be included in our model (see section 2.2 below).

Given that most of these variables are non-stationary according to unreported augmented Dickey-Fuller (ADF) unit root tests ${ }^{5}$ the use of models that involve stationarity inducing transformations, such as differencing and cointegrating linear combinations of variables, is desirable. Stationary vector autoregression (VAR) and vector error correction models (VECM) are, therefore, typically employed to assess the impact of covariates on bond yields. We do not employ the standard Johansen VECM cointegration method because it is well known to only be appropriate for a moderate number of variables (certainly less than 16) in the cointegrating equation and can become easily overparameterized (and overfit the data) which would

\footnotetext{
${ }^{4}$ Recent research regarding the expectations hypothesis supports our view that it is possible that demand can influence long term yields. Sarno et al. (2007), for example, find that the expectation hypothesis can be rejected "throughout the maturity spectrum from one month to 10 years" (p. 82). Tang and Xia's (2007) research confirms this finding.

${ }^{5}$ Even though the ADF test has low power, inspection of data plots and knowledge of the data suggest that most of our variables are intrinsically I(1). Exceptions are the (log of the) ISM-Index, the MOVE Index, and the corporate bond holdings ratio from US individuals, which are stationary according to ADF tests.
} 
unacceptably reduce the degrees of freedom in our application. ${ }^{6}$ Further, the Johansen procedure requires that all variables entering the potential cointegrating equation be integrated of order one - which is not certain in our application.

Widely used existing macro-finance models of the term structure (see Bernanke, Reinhart and Sack, 2004 [BRS hereafter]; Rudebusch et al., 2006; Rudebusch and Wu, 2008 [hereafter RW]; Eijffinger et al., 2010; Rudebusch, 2010) also have their limitations. VAR based macro-finance models such as that given in BRS involve a nonlinear estimation procedure that is implemented in two stages in an attempt to reduce the number of parameters that must be estimated nonlinearly. ${ }^{7}$ In the first stage a VAR (that is linear in parameters) is estimated by OLS. The coefficients from this model are taken as given and are used in a stochastic pricing kernel equation which, in the second stage, is estimated by nonlinear least squares to produce the risk factor loadings. Due to the large number of parameters that this estimation procedure involves, the number of variables included in the VAR is constrained - see Eijffinger et al. (2010). Indeed, this method may produce models that overfit the sample due to the large number of parameters. It would not be possible to estimate a BRS-type model with our data for the 16 variables that we wish to consider due to degrees of freedom constraints - the need to accommodate structural breaks would exacerbate this problem. In contrast, the ARDL method that we adopt has the advantage of being able to estimate all parameters simultaneously (with structural breaks) in a linear functional form with OLS rather than using a two-step procedure. The BRS model also has an issue with the internal inconsistency of forward-looking expectational variables and the forecasts produced by the VAR (Rudebusch et al., 2006).

\footnotetext{
${ }^{6}$ Our model has potentially twice as many variables in the cointegration equation because we also allow parameter shifts in our equilibrium equation.

${ }^{7}$ As Rudebusch et al. (2006) point out "Estimation of the bond-pricing implications of the model is thus highly nonlinear and can be tricky in practice, with a great many local minima." Eijffinger et al. (2010) also highlight the difficulty in optimizing the likelihood function with this method as well as noting the homoscedastic yields implied by this method.
} 
Another form of macro-finance model that has been popular in the literature is the New Keynesian specification developed by RW. This method is based upon a model that uses latent factors, in particular the level of the yield curve and the (negative of the) yield curve slope, as the components of the interest rate to be modeled. This approach has been criticized because such factors have no economic interpretation (see Rudebusch, 2010), nevertheless RW use a form of this model that has economic underpinnings. That is, the slope component is based on a Taylor rule with a serially correlated error term while the level component reflects the medium term inflation target and short term variations in inflation. These components are jointly determined with forward-looking New Keynesian type equations for inflation and the output gap - there are three macroeconomic variables in the specification (interest rates, inflation and the output gap). This is a more structural framework that reduces the number of parameters relative to BRS such that it can be estimated in a single step by maximum likelihood. However, this is done at the expense of the number of explanatory determinants that are considered, which is relatively limited. $^{8}$

Existing models that are based upon the BRS and RW approaches have not explained much of the bond yield conundrum. ${ }^{9}$ We will employ the ARDL single equation bounds testing cointegration method (that corrects for weak endogeneity of regressors) introduced by Pesaran et al. (2001) and developed by Shin et al. (2013). Our approach seeks to explain the conundrum by addressing the shortcomings of these models. In particular, our ARDL model will incorporate (simultaneously) a much larger number of explanatory determinants than is feasible with the BRS and Johansen methods or that have been previously employed in RW models. Further, our

\footnotetext{
${ }^{8}$ Rudebusch et al. (2006) indicate that in their application the RW model has 17 parameters to estimate compared to 125 for the BRS model.

${ }^{9}$ To our knowledge macro-finance models of the term structure of interest rates were not able to solve the 'bond yield conundrum'. For a discussion of macro-finance models of the term structure of interest rates see Diebold et al. (2005) and Rudebusch et al. (2006). See Kim (2007) for a thorough discussion of the shortcomings of this approach.
} 
model does not rely on the identification of latent factors (as with RW) that, at best, have limited economic underpinnings. The OLS estimation method that we use can be applied in one step and does not suffer from optimization problems as is the case with the BRS model. Our model can also be easily adapted to allow for structural shifts based upon an application of the Shin et al. (2013) model that incorporates cross-products of covariates and zero-one dummy variables. Modeling parameter shifts would not be as easily implemented, especially given the degrees of freedom constraints, with the other methods discussed above.

We therefore use the single equation ARDL framework because it can incorporate a broader set of explanatory factors than has previously been considered whilst simultaneously accounting for the parameter shifts identified in the literature in a single model that can be estimated in one stage. Indeed, this is the only means to conduct our investigation of so many potential explanatory factors given current data constraints. Further, this specification turns out to be more successful in explaining the bond yield conundrum than the methods previously employed in the literature. Consequently, we use four ARDL models in (unrestricted) error correction mechanism form to test which of the above stated determinants were mainly responsible for the low long term yields of AAA rated US bonds. This approach represents a novelty of this paper.

The general form of our models is:

$$
\Delta y_{t}^{l}=\beta_{0}+\sum_{i=0}^{p} \gamma_{1 i} \Delta X_{1 t-i}+\cdots+\sum_{i=0}^{p} \gamma_{K i} \Delta X_{K t-i}+\sum_{i=1}^{p} \alpha_{i} \Delta y_{t-i}^{l}+\alpha_{0} y_{t-1}^{l}+\sum_{k=1}^{K} \beta_{k} X_{k t-1}+u_{t}
$$

This modeling approach takes into account current and lagged differenced variables to measure short run effects and lagged level variables to account for long run effects, and it allows us to include all of the above stated determinants without losing too many degrees of freedom. Another important advantage of this modeling technique is that, in contrast to VECMs, it 
produces consistent estimates of the long run coefficients independently of their order of integration (Pesaran and Shin, 1995) ${ }^{10}$. This is important in our application given that unit root tests suggest a mixture of $\mathrm{I}(1)$ and $\mathrm{I}(0)$ variables in our model.

\subsection{Data}

For each of the above listed determinants a proxy is chosen that is either the same as, or similar to, that used in previous studies. Considering that most of the relevant data is not available on a daily or weekly basis, monthly data are utilized to ensure sufficient degrees of freedom ${ }^{11}$. As proxies for US long term interest rates of highly rated fixed income securities we take the 10-year Treasury yield (retrieved from the Federal Reserve Statistical Release H.15), the 10-year agency bond yield, and the average yield of Moody's bond index for AAA rated corporate bonds and for AAA rated 10-year municipal bonds (all retrieved from Bloomberg).

To account for changes in the US short term interest rate we include the 3-month rate for Eurodollar deposits in London (Federal Reserve Statistical Release H.15). Following Warnock and Cacdac Warnock (2009), we see the Eurodollar rate as a preferable measure for changes in current monetary policy inasmuch as it varies more than the federal funds rate. As a proxy for current and expected inflation we include the trimmed personal consumption expenditure (PCE) deflator, following Bandholz et al. (2009), and the ten year consumer price index (CPI) inflation expectations, as in Warnock and Cacdac Warnock (2009). Data are taken from the Survey of Professional Forecasters and the Philadelphia Fed respectively.

\footnotetext{
${ }^{10}$ The ARDL form that we adopt has additional advantages. First, it possesses small sample power dominance in terms of testing cointegration over Engle and Granger type tests and, second, the model corrects for any weak endogeneity of regressors see, for example, Shin et al. (2013). A further point is that we can simultaneously estimate and test structural breaks in both the long run and short run components of the ARDL model in a simple manner. The application of this method with the inclusion of structural breaks is a novelty of this paper.

${ }^{11}$ While monthly series do exist for most of the data some are only available on a quarterly basis and are therefore interpolated to monthly frequency with the "cubic match last" method, which is readily available in EViews. The variables which have been interpolated are: 10-year inflation expectations, domestic bond holdings, and the data on outstanding bonds (with the exception of Treasuries). The available data on the expected deficit-to-GDP ratio are only published twice each year by the CBO and are therefore also interpolated, in line with Warnock and Cacdac Warnock (2009).
} 
To capture the state of the business cycle, the purchasing manager index from the Manufacturing Survey of the Institute for Supply Management (ISM) is used, as in Bandholz et al. (2009). This is because "[f]inancial market participants have anxiously anticipated the ISM ever since Alan Greenspan once claimed ... that he placed great emphasis on this report" (Trainer, 2006, p. 211). When the ISM-Index is relatively high (> 50) market participants expect high growth figures and when the ISM-Index is relatively low $(<43)$ a recession is anticipated. As a proxy for changes in the stock market - which is seen as a good indicator of the business cycle and for shifts in portfolio preferences (Idier et al., 2007) - we employ the Dow Jones Index (retrieved from yahoo finance).

We use the following data to measure changes in default risk perceptions, financial market volatility and macroeconomic uncertainty. Default risk is captured by using data about expected fiscal policy, which is measured by 5-year-ahead deficit-to-GDP expectations as in Laubach $(2009)^{12}$ (retrieved from the CBO Budget and Economic Outlooks) and the expected default risk of AAA rated corporate bonds. The latter is proxied by the Expected Default Frequency (EDF) for AAA rated corporate bonds (kindly provided by Moody's Analytics UK) as in Krishnamurthy and Vissing-Jorgensen (2007). Analogous to Rudebusch et al. (2006) data from the Merrill Lynch Option Volatility Estimate (MOVE) Index, retrieved from Bloomberg, are used to account for financial market volatility ${ }^{13}$. Furthermore, the 24-month rolling standard deviation of the Eurodollar rate, the Chicago Board Options Exchange Volatility (VIX) Index (retrieved from Bloomberg), and two measures for macroeconomic uncertainty (the 24-month

\footnotetext{
${ }^{12}$ It can be difficult to measure the impact of the actual deficit-to-GDP ratio because automatic stabilizers lead to an increase of deficit levels in recessionary periods, while monetary easing can at the same time be expected to lower the long term yield. Laubach (2009) has therefore proposed using expected deficit-to-GDP ratios as these are more likely to mirror investor's expectations which are important in regard to long term yields.

${ }^{13}$ For non-Treasury bonds the significance of the 24-month rolling standard deviations of changes in the long term yields are tested, similar to Warnock and Cacdac Warnock's (2009) approach, but these proxies are insignificant.
} 
rolling standard deviation of the ISM-Index and of the ten year CPI inflation expectations) are tested for significance, similar to Rudebusch et al. (2006).

To measure the influence of changes in investor demand on bond yields, private and foreign official holdings as a ratio of total outstanding bonds are taken into account, as in Rudebusch et al. (2006) and Bandholz et al. (2009). The holdings ratio is preferable to mere flow or stock figures because demand pressure can be expected to take place only when investors increase their holdings disproportionally to newly available bonds (i.e. if their holdings ratio increases). The data for changes in the holdings from US banking institutions, US individuals and US institutional investors are retrieved from the Flow of Funds statistics ${ }^{14}$. The data for foreign official and foreign private long term holdings are taken from the Treasury International Capital Reporting System (TIC) ${ }^{15}$ because the Flow of Fund statistics do not distinguish between official and private holdings. The amount of total outstanding bonds is retrieved from the Flow of Funds tables and from the Treasury Bulletins (outstanding notes, bonds and TIPS).

\subsection{Sample Period}

Most previous studies take the mid-1980s to mid-2000s as their sample period. In contrast, we limit our sample period to that spanning February 1994 to June 2007 (with the exception of the agency bond model where the yield data are only available from 1995 onwards). February 1994 has been chosen as the starting point because the data on foreign official holdings show a structural break at that time - presumably the break can be attributed to the devaluation of the Renminbi from $5.8 ¥ / \$$ to $8.7 ¥ / \$$ between December 1993 and January 1994. Another reason is provided by Thornton (2007) who presents evidence that a structural break might have occurred

\footnotetext{
${ }^{14}$ Federal Reserve Statistical Release: Tables L209, L210, L211 and L212.

${ }^{15}$ Holdings in the TIC data are only reported semi-annually. Therefore, estimations from the Fed about monthly changes in holdings are used. The source for these data is: http://federalreserve.gov/pubs/ifdp/2007/910/ticdata.zip.
} 
in 1994 when the FOMC started to release policy statements after its meetings. This change has influenced expectations to a significant degree (Bernanke et al., 2004). June 2007 has been chosen as the last observation because subprime "problems started to become evident on Wall Street and London in June 2007 [when] Bear Sterns' highly leveraged mortgage-backed securities funds lost virtually all their value and ultimately filed for bankruptcy" (Dwyer and Tkac, 2009, p. 1301). ${ }^{16}$

\subsection{Model selection}

Treasury yield model. - First, we model the 10-year Treasury yield based on the variables described above. Due to the multitude of potential variables that could be included, the following model was constructed that incorporated contemporaneous differenced and level proxies of variables that were significant in the models of previous studies:

$$
\begin{aligned}
\Delta y_{t}^{l}= & \beta_{0}+\beta_{1}\left(\Delta F O_{t}\right)+\beta_{2}\left(\Delta F P_{t}\right)+\beta_{3}\left(\Delta P_{t}\right)+\beta_{4}\left(\Delta i_{t}\right)+\beta_{5}\left(\Delta \text { lism }_{t}\right)+\beta_{6}\left(\Delta \pi_{t}\right) \\
& +\beta_{7}\left(\Delta \pi_{t}^{10}\right)+\beta_{8}\left(\Delta \text { dow }_{t}\right)+\beta_{9}\left(\Delta \text { move }_{t}\right)+\beta_{10}\left(\Delta d e f_{t}^{5}\right)+\beta_{11}\left(y_{t-1}^{l}\right) \\
& +\beta_{12}\left(F O_{t-1}\right)+\beta_{13}\left(F P_{t-1}\right)+\beta_{14}\left(P_{t-1}\right)+\beta_{15}\left(i_{t-1}\right)+\beta_{16}\left(\text { lism }_{t-1}\right) \\
& +\beta_{17}\left(\pi_{t-1}\right)+\beta_{18}\left(\pi_{t-1}^{10}\right)+\beta_{19}\left(\text { dow }_{t-1}\right)+\beta_{20}\left(\text { move }_{t-1}\right)+\beta_{21}\left(\text { def }_{t-1}^{5}\right)
\end{aligned}
$$

where ${ }_{t}$ indicates the current period, ${ }_{t-1}$ denotes a one month lag, $\Delta$ is the difference operator, $y^{l}$ is the nominal 10-year Treasury yield, FO are foreign official holdings as a ratio of total outstanding long term Treasuries, FP are foreign private holdings as a ratio of total outstanding

\footnotetext{
${ }^{16}$ To check for the robustness of our results (discussed in Section 3) we also re-estimated our parsimonious models (reported in Table 2 and Table 3) over two different sample periods: January 1996 to June 2007 and February 1994 to December 2005 (for the agency bond yield the sample is January 1995 to December 2005). Overall the models are generally stable: estimating these 8 models over these shorter sample periods does not greatly introduce misspecification. The signs of all 91 variables are unchanged relative to the models estimated over the full sample period and only 13 of the 89 individually significant variables become insignificant at the 5\% level. With regard to the demand variables only 4 out of 24 become insignificant and 3 of these have tratios above 1.57 in magnitude. The other 20 demand variables remain significant and have similar magnitudes in the models estimated over all three time periods. We are therefore confident that our overall conclusion that investor demand is important in explaining the 'bond yield conundrum' is not biased by the sample period chosen. Indeed, when changing sample periods one would expect some changes in results, however, the issue is how major are these changes to the fundamental conclusions of the paper. We find that the changes are relatively minor and do not alter the fundamental conclusions of our paper. Hence, we present our results as robust.
} 
long term Treasuries, $P$ are US pension fund holdings as a ratio of total outstanding long term Treasuries, $i$ is the 3-month Eurodollar rate, lism is the log of the ISM-Index, $\pi$ is the actual PCE inflation rate, $\pi^{10}$ are 10-year CPI inflation expectations, dow is the value of the Dow Jones Index, move is the MOVE Index, and def $f^{5}$ are 5-year deficit-to-GDP expectations.

However, when estimated this model suffered from autocorrelation suggesting that the yield might be influenced by some differenced variables with a time lag. The monthly frequency of our data suggests consideration of up to twelve lags of each of the variables. However, all twelve differences of all of the variables in (3) could not be included simultaneously. We therefore added the twelve lagged differences of just one variable in (3) and, based on an F-test, excluded the jointly insignificant lags of the differences of this variable. This was repeated in turn for each of the variables in (3), including the dependent variable, until a model that included only significant lags of the differences of all variables was obtained. Finally, all level variables which were jointly not significant at the $5 \%$ level were removed from the model.

Variable addition tests were then conducted on the following variables not included in (3): VIX Index and the 24-month rolling standard deviation of the Eurodollar rate, ISM-Index, and ten year CPI inflation - the first lagged levels and twelve lagged differences being considered for each factor. However, all of these variables are jointly insignificant at the $5 \%$ level, which is in line with the results of Rudebusch et al. (2006, p. 25) who find that from the volatility variables "[t]he most significant and robust explanatory variable is the implied volatility on longer-term Treasuries." (i.e. the MOVE Index). The resulting model (reported as (i) in Table 2 in the Results section) shows no evident misspecification at the 5\%-level in terms of autocorrelation (lags 1...12), non-normally distributed residuals and heteroskedasticity [Arch (lags 1...12) and White tests]. According to Ramsey's Reset test the appropriate functional form is linear and the $\mathrm{Wu}-$ 
Hausman test indicates that all contemporaneous variables are weakly exogenous. Further, the bounds test (with unrestricted intercept) - critical values are taken from Pesaran et al. (2001) confirms that the level variables are mutually cointegrated irrespective of whether the regressors are $\mathrm{I}(0)$ or $\mathrm{I}(1) .{ }^{17}{ }^{18}$ Hence there is no issue of spurious regression and inference from the various statistics (including t-ratios) is regarded as valid.

However, unreported CUSUM and CUSUM of Squares Test indicate a structural break. This is in line with the findings of ECB (2006), which reports a structural change in 1999, and Wu (2005) who finds a structural break between 2000 and 2002. ${ }^{19}$ Therefore, a Quandt-Andrews breakpoint test (35\% trimming) was undertaken. According to this test, the maximum likelihood for a break is in November 1998, although a break is only indicated at the $10 \%$ level. Considering this result and the results of past studies we believe that it is reasonable to consider the possibility of a break in November 1998. The main reason for the break at this time is probably that in 1999 the "strong accumulation of reserves" started (ECB, 2006, p. 56) while at the same time the holdings ratio of foreign private investors declined (with the exception of the period October 1999 to January 2000).

\section{[Insert Table 1 here]}

\footnotetext{
17 The F-test applied with unrestricted intercept deletes all lagged level terms (but not the intercept) from the model - the number of lagged level terms (excluding $y_{t-1}^{l}$ ) determines the degrees of freedom. For the F-test and t-test the critical values corresponding to the $\mathrm{I}(1)$ bound are reported in the table because breaching these values confirms cointegration regardless of the variables' order of integration.

${ }^{18}$ Pesaran et al. (2001) propose both an F-test (Wald test) and a t-test for the null of no cointegration. The t-test tests the null by only testing whether the coefficient on the lagged dependent variable, $y_{t-1}^{l}$, is zero. If the null hypothesis is false, the magnitude of the t-test should be large enough to reject the null. However, Pesaran et al. (2001, p. 304) point out that rejection of the null based on the t-ratio of $y_{t-1}^{l}$ does not exclude the possibility that only some (or even none) of the explanatory variables cointegrate with the dependent variable. This needs to be borne in mind when the bounds t-test indicates support for cointegration, as in our case. Further, because the t-test for cointegration does not indicate which explanatory variables, if any, cointegrate with $y_{t-1}^{l}$ the t-ratios of the lagged level variables (except $y_{t-1}^{l}$ ) should be interpreted with caution - they can follow two different limiting distributions.

19 Other papers that identify the need to account for potential parameter changes include Eijffinger et al. (2010) and Rudebusch (2010).
} 
To model the structural break, shift variables for all the significant independent variables were created with the value zero before the break and the original value of the variable after the break $^{20}$. All of these shift variables were jointly included in the model. The jointly insignificant variables were subsequently excluded (first the shift variables and then the non-shift variables) to obtain the final parsimonious model. This model (reported as (ii) in Table 2) has a superior fit to the model without a break, no misspecification is evident and its level variables are mutually cointegrated $^{21}$. Further, the CUSUM and CUSUM of Squares Test indicate no other structural break after November 1998 (the Quandt-Andrews test cannot be effectively applied in this model because of the shift variables).

Agency, corporate and municipal yield models. - The model selection procedure for the other bond models is essentially the same as that for the Treasury yield model. In addition to the macroeconomic and risk variables that are significant in the Treasury model, the 24-month rolling standard deviation of changes in the long rates for each bond class and the EDF for AAA rated corporate bonds were tested for significance (again with lags $1 \ldots 12$ for the differenced variables). Furthermore, we also controlled for an increase in foreign and domestic investor demand for each bond class ${ }^{22}$, and considered whether the lagged level and differences of the 10-

\footnotetext{
${ }^{20} \mathrm{We}$ are aware that the switch from one regime to another may occur over a period of time, perhaps in a smooth transition. However, to model only a one time shift provides a better approximation than to not include a shift at all (which is a shortcoming in other recent studies on the topic, as we will discuss in more detail at the end of the next section). Therefore, we think that our work is an important development and it is the best we can do at the moment taking into account the degrees of freedom problem that we are facing.

${ }^{21}$ Because the shift variables are related to the non-shift variables the degrees of freedom for the cointegration test are uncertain. One could, for example, either treat the shift and non-shift components of a particular variable as one covariate or two separate variables for calculating degrees of freedom. Following Shin et al. (2013) we consider critical values using degrees of freedom calculated in both of these ways, thereby forming further upper and lower bounds of the test for the already existing upper and lower bounds (related to uncertainty over the variables' orders of integration). If the F-statistic (t-ratio) exceeds (is below) the critical value's bound for I(1) processes treating shift and non-shift components of a variable as one (two) covariate(s) there is unambiguous evidence of cointegration and we use these criteria in our application. We extrapolate some of the critical values reported in Pesaran et al. (2001) when the number of variables used to calculate the degrees of freedom exceed 10 . We also note that the use of this cointegration test in a model allowing for structural breaks represents one of the novelties of this paper.

${ }^{22}$ Only those investor groups that had significant holdings in June 2007 (i.e. only investor groups with a holdings ratio of above $1 \%$ ) and that increased their holdings ratio in the respective bond class during the 'conundrum' period were included in each model.
} 
year Treasury bond yield influence the long term yields of these bond classes ${ }^{23}$. Having established parsimonious models for agency, corporate and municipal bond yields, breakpoint tests were carried out. In line with the Treasury model, the Quandt-Andrews breakpoint test indicates a structural break in each non-Treasury model at least at the $10 \%$ level. $^{24}$ The indicated dates of the structural breaks are relatively close to the Treasury model's date (i.e. within a range of 9 month). We therefore consider the possibility of a break in the non-Treasury models by including shift variables in line with the procedure described above.

The resulting parsimonious models (reported in Table 3) show no evident misspecification and the level variables are mutually cointegrated. All of our favored models for inference include shift variables and are discussed in the next section. Due to space limitations only the models that account for the structural break are presented for the agency, corporate and municipal bond yields (all of these models have a superior fit compared to those without a break). The long run solutions for our favored parsimonious dynamic models (with breaks) are reported in Table 4 (the equilibrium coefficients' standard errors are obtained as discussed in De Boef and Keele, 2008).

\section{Results}

\subsection{Treasury yield model}

The results of the Treasury model confirm previous findings that an increase in the demand from foreign governments had a negative impact on the long term Treasury yield (Table 2). According to our favored model for inference, model (ii), an increase in foreign government

\footnotetext{
${ }^{23}$ Originally we did not include the Treasury yield as explanatory variable in our non-Treasury models. However, we found that the Treasury yield is highly significant and that the models including this variable exhibit both a superior fit and a lower Schwartz criterion. The results for the non-Treasury models excluding the Treasury yield are available upon request.

${ }^{24}$ We note that according to unreported Chow tests there is no structural break in June 2004, when the 'conundrum' period started, for any of the models that we report. This breakpoint is not specified with reference to the data, it is a date of $a$ priori interest.
} 
demand had a consistently negative impact on the 10-year US Treasury yield throughout the whole sample period in the short and long run. That is, ceteris paribus, an increase of the foreign official holdings ratio by $1 \%$ point had a negative impact on the yield of around 9 basis points (bp) in the long run. This magnitude is similar to the 7bp impact that Bandholz et al. (2009) and Bertaut et al. (2011) found in their models ${ }^{25}$. Foreign private investor holdings also had a negative impact in the long run before November 1998 but their impact became insignificant thereafter. The most likely explanation for this change is that although between August 1994 and November 1998 the holdings ratio of foreign private investors increased steadily (by a total of $11 \%$ points), after the latter date it began to decline (for example, it declined by $3.5 \%$ points in the 'conundrum' period June 2004 to June 2007). Hence, private investors put no further demand pressure on the yield in the post-break period.

\section{[Insert Table 2 here]}

All the control variables have the expected signs and reasonable magnitudes. The short term interest rate has a positive impact in both the short run and the long run, but after November 1998 this impact becomes much smaller in both cases. This finding supports Stiglitz and Greenwald's (2003) argument that financial innovation fostered a decoupling of long term interest rates from short term rates. To be specific, we find that, ceteris paribus, before November 1998 a $1 \%$ point increase in the short term interest rate leads to a $45 \mathrm{bp}$ increase in the Treasury yield in the long run, with this impact declining to $11 \mathrm{bp}$ after this date. These magnitudes are in line with other studies, e.g. Warnock and Cacdac Warnock (2009) who find

\footnotetext{
${ }^{25}$ Bandholz et al. (2009) use total foreign Treasury holdings as measurement and Bertaut et al. (2011) use foreign official holdings of Treasuries and agency bonds.
} 
that the impact is $37 \mathrm{bp}$ (but who do not consider a possible shift in the relationship between short term and long term interest rates).

Higher growth expectations are also found to lead to an increase in the Treasury yield, but here again the impact becomes smaller after the break: thus, ceteris paribus, in the 'conundrum' period a $1 \%$ increase of the ISM Index raised the yield by about $2.5 \mathrm{bp}$. This result is similar to Bandholz et al. (2009) who report an impact of about 2bp. In contrast, the long run impact of inflation, stock prices and the volatility of Treasuries on the yield remains unchanged throughout the whole period. Ceteris paribus, a $1 \%$ point rise in the PCE deflator increases the yield by 94bp, a 1000 point increase in the Dow Jones Index raises the yield by 45bp (in line with Idier et $a l ., 2007$, who find that a $1 \%$ increase in stock returns has an impact of $42 \mathrm{bp}$ ) and an increase of the MOVE Index by 10 points increases the yield by $7 \mathrm{bp}$ in the long term.

In order to make these results more palpable and identify which of the variables included in the Treasury model (ii) were responsible for the 'bond yield conundrum' the marginal cumulative impact $\left(\mathrm{MCI}^{26}\right)$ of each of these variables on the Treasury yield is used. June 2004 to June 2007 is chosen as the reference period for this exercise because it spans the beginning of US monetary tightening and the subsequent debate on the 'bond yield conundrum'. The MCI of each variable depends on the coefficients, $\beta_{\gamma i}$, (including the changes due to the break where applicable) of the differenced and lagged level of this variable as well as the variable itself, $\gamma_{t}$. Thus, the formula for calculating the MCI for each month is:

$$
\begin{gathered}
\text { Impact }_{\gamma t}=\beta_{\gamma 1} \Delta \gamma_{t}+\beta_{\gamma 1}^{\text {shift }} \Delta \gamma_{t}+\cdots+\beta_{\gamma 12} \Delta \gamma_{t-12}+\beta_{\gamma 12}^{\text {shift }} \Delta \gamma_{t-12}+\beta_{\gamma 13} \gamma_{t-1}+\beta_{\gamma 13}^{\text {shift }} \gamma_{t-1} \\
M C I_{\gamma t}=\text { Impact }_{\gamma t}-\text { Impact }_{\gamma 2004: 05}
\end{gathered}
$$

\footnotetext{
${ }^{26}$ The MCI is the difference in a particular variable's contribution to the yield in any particular period relative to a reference point (in our case May 2004).
} 
Figure 3 shows that foreign official demand has the largest negative MCI on the yield in the reference period, which can therefore be seen as mainly responsible for the 'conundrum', while foreign private demand by contrast had virtually no impact in this period. Our model's finding that the increase in foreign official Treasury holdings reduced the yield by as much as $60 \mathrm{bp}$ during the 'conundrum' period is similar to previous findings: Bandholz et al. (2009) report an impact of 70bp between 2003 and 2006, Craine and Martin (2009) one of 80bp between 2004 and 2006, and Warnock and Cacdac Warnock (2009) one of 80bp between 1984 and May $2005^{27}$. In addition to foreign official demand, pessimistic expectations about the business cycle (ISM Index) and a decrease of the implied yield volatility (MOVE Index) also had a negative impact on the Treasury yield of about 20bp each and therefore also partly explain the 'conundrum'. Counteracting these factors were the increases in short term interest rates and in core price inflation, both of which had a small positive impact of about $20 \mathrm{bp}$, and the rise in stock prices, which had a relatively larger positive impact of almost $60 \mathrm{bp}$.

\section{[Insert Figure 3 here]}

According to the implied yield of our favored model, which fits the actual Treasury yield remarkably well during the 'conundrum' period, these forces seem to explain the 'conundrum' fully (see Figure 4 for the yield residuals) ${ }^{28}$. Thus, our model improves upon existing Treasury bond models. For example, ECB (2006), Rudebusch et al. (2006), Warnock and Cacdac Warnock (2009), Eijffinger et al. (2010), and Rudebusch (2010) all report that their models

\footnotetext{
${ }^{27}$ These reported impacts are of course influenced by the chosen reference point. If February 1994 is taken as the starting point foreign official demand will be found to have lowered the 10-year Treasury yield by as much as $128 \mathrm{bp}$ in the 'conundrum' period. However, if January 2003 is taken as the starting point the size of the impact is $70 \mathrm{bp}$, exactly the amount reported in Bandholz et al. (2009).

${ }^{28}$ The residuals of the yield have been calculated as follows: actual yield - fitted yield $\left(\right.$ where fitted yield t $_{t}=\Delta{\text { fitted } y i e l d_{t}+}^{+}$ actual yield $_{t-1}$ ).
} 
overestimate the long term Treasury yield after June 2004, while Bandholz et al.'s (2009) model overvalues the yield throughout the year $2005^{29}$.

\section{[Insert Figure 4 here]}

The reason why our model appears to explain the Treasury yield 'conundrum' better than previous models most likely lies in our different modeling strategy. In contrast to the previous literature, we consider more variables in our model (whilst accounting for non-stationarity) and we model the evident structural break. Indeed, Rudebusch et al. (2006), Eijffinger (2010), and Rudebusch (2010) use a VECM model that does not directly include foreign official demand ${ }^{30}$, which our model found to be the most important variable in explaining the 'conundrum'. Furthermore, the above authors do not take into account the possibility that the impact of the short term interest rate on the 10-year Treasury yield during the 'conundrum' period was smaller than before November 1998.

The incorporation of this possibility in our model also seems to provide a major explanation of why it fits the yield better than do the models of Bandholz et al. (2009) and Warnock and Cacdac Warnock (2009). These authors' models attribute a higher impact than our model does to the short term interest rate during the 'conundrum' period (with long run coefficients of 0.37 and 0.33, respectively). An additional point is that these authors' studies appear to overestimate the yield either because they do not include a measure for interest rate volatility (Bandholz et al.) or because they use the rolling standard deviation of long yields to proxy the volatility of yields

\footnotetext{
${ }^{29}$ Not all existing studies report their model residuals, see e.g. Idier et al. (2007), and Craine and Martin (2009).

${ }^{30}$ Rudebusch et al. (2006) test if foreign official demand is correlated with the error term of their model, and find no correlation - they use custodial data from the New York Fed (FRBNY) as a proxy for foreign official holdings; this seems not be the best proxy because "... some foreign governments avoid the FRBNY and thus this source is best described as only partial" (Warnock and Cacdac Warnock 2009, p. 905). However, this finding does not imply that the model results would be the same if the variable is fully incorporated in the model.
} 
(Warnock and Cacdac Warnock) - in contrast to the MOVE Index, the rolling standard deviation does not indicate a decline in volatility during the 'conundrum' period.

\subsection{Agency, corporate and municipal bond yield models}

The results of the agency, corporate and municipal yield models clearly indicate that investor demand played a major role in explaining the low long term yields of non-Treasury AAA rated bonds (Table 3 and Table 4). In line with the Treasury yield model, these models fit the data well in the 'conundrum' period (see Figure 4), and all control variables have the expected signs. However, in some cases the magnitudes notably differ. Next to noise, the most likely explanation for this observation is that investors do not see these different bond classes as perfect substitutes and therefore ask for different adjustments in prices when conditions are changing. Indeed, previous studies confirm that investors value different bond classes differently even while they may carry the same credit rating (see e.g. Krishnamurthy and Vissing-Jorgenson, 2007). A likely explanation for why the impact of the control variables is lower than in the Treasury equation is that part of their impact is indirectly captured via the inclusion of the 10-year Treasury yield in the non-Treasury yield models (where the former is influenced by the same control variables as the latter). The additional control variable, the proxy for default risk of AAA rated corporate bonds (EDFAAA), has a reasonable magnitude as we will see below.

[Insert Table 3 here]

[Insert Table 4 here]

Agency bond yield. - Foreign official demand had a negative impact not only on the Treasury yield but also on the agency bond yield, though only in the short run (Table 3, column 1). By contrast, an increase in the demand from foreign private and US individual investors has 
negative short and long term effects on the 10-year agency bond yield, while the demand from US pension funds only has negative long term effects (Table 3 and Table 4, column 1). All demand variables remain stable over the whole sample period. The immediate effect of an increase in the holdings ratio of foreign official investors by $1 \%$ point was a reduction of the agency yield by $98 \mathrm{bp}$. Each $1 \%$ point increase in the foreign private holdings ratio led to a decline in the yield of around $21 \mathrm{bp}$ in the long run, while the same increase in the domestic pension fund and individual holdings ratio lowered the yield by around 10bp and 3bp, respectively. Possible explanations as to why the magnitudes of the coefficients of these investor groups were so different are that they reacted differently to expected changes in the agency yield or that they had different expectations of future yields. US individual investors, for example, might have increased their holdings to a lesser extent than foreign private investors when they (rightly) expected the agency yield to decrease and hence put less additional pressure on yields than their counterparts.

Changes in the Treasury yield are also very important in explaining changes in the agency yield: a $1 \%$ point decrease in the 10 -year Treasury yield lowers the 10 -year agency yield by $87 \mathrm{bp}$ in the long term and by around 103bp in the short term, i.e. changes in the Treasury yield are nearly transmitted one to one to the agency yield. This result indicates that investors see agency bonds as a very close substitute for Treasury bonds.

The MCI suggests that between June 2004 and mid-2005 the fall of the 10-year Treasury yield was the main reason for the low long term agency yield (up to -64bp), while after October 2005 investor demand became the main depressing force (up to $-72 \mathrm{bp}$ ). In contrast to the Treasury yield model most of the time private investors had a similar negative impact on the yield than foreign official investors. The downward pressure on yields, further fuelled by a lowering of the 
implied yield volatility (up to -23bp), was partly offset by the rise in the short term interest rate, and by the increase in stock prices and in core price inflation (Figure 5).

\section{[Insert Figure 5 here]}

Corporate bond yield. - Foreign private investors invested heavily in the corporate bond market between 1994 and mid-2007, their holdings ratio more than doubling (from 11\% to $24.5 \%$ ) during this period, with the result that they put significant downward pressure on AAA rated corporate bond yields in the short run (Table 3, column 2) and in the long run (Table 4, column 2). Regarding the long run, an increase in the foreign private investors' holdings ratio by $1 \%$ point led to a decrease of the yield by about $6 \mathrm{bp}$. As in the agency yield model, US individual investor holdings also had a negative impact on the yield when they increased their holdings ratio (about $5 \mathrm{bp}$ in the long run). Additionally, an increase in the holdings ratio of banks lowered the corporate bond yield in the short run.

Interestingly, the impact of the 10-year Treasury yield on the corporate bond yield is around 20bp lower than in the agency yield model (i.e. a 1\% point increase in the former 'only' leads to a $67 \mathrm{bp}$ increase of the later in the long term and a $82 \mathrm{bp}$ increase in the short term). In other words, seemingly AAA rated corporate bonds are not as close a substitute for Treasuries as agency bonds are.

In line with the agency bond MCIs, the nominal AAA rated corporate bond yield MCIs shows that initially the drop in the 10-year Treasury yield was the main factor in explaining the low long term corporate bond yields, while after some time investor demand became the main suppressing force (Figure 6). Between June 2004 and June 2007 the yield of AAA rated corporate bonds was lowered by as much as $28 \mathrm{bp}$ due to the decline of the Treasury yield and by 
as much as $19 \mathrm{bp}$ due to an increase in the demand pressure from foreign and domestic private investors. Lower yield volatility and especially a lower default risk for AAA rated corporate bonds added significantly to this pressure. The main counteracting force was the increase in the short term interest rate.

\section{[Insert Figure 6 here]}

Municipal bond yield. - Finally, an increase in foreign and domestic private demand for 10year AAA rated municipal bonds also had a negative long term impact on their yield. It appears that a $1 \%$ point increase in the holdings ratio of foreigners decreased the municipal bond yield by 20bp (Table 4, column 3). In addition, domestic individual investors and insurance companies put downward pressure on the yield in the magnitude of $4 \mathrm{bp}$ and $10 \mathrm{bp}$, respectively, when they increased their holdings ratios by $1 \%$ point (the differences in the impact possibly stemming from different expectations or from differences in the reactions to expectations as previously argued). These long term impacts are stable over the whole period.

Changes in the 10 -year Treasury yield also have a significant impact, i.e. a $1 \%$ point increase in the Treasury yield led to a $44 \mathrm{bp}$ increase in the municipal bond yield. One possible reason why the impact is notably smaller than in the other two non-Treasury models is the special tax status of municipal bonds ${ }^{31}$, which makes a direct comparison with other bond yields complicated and means that investors probably see municipal bonds as the least best Treasury substitute (in comparison with agency and AAA rated corporate bonds). Nevertheless, it is interesting to note that the short term impact of changes in the Treasury yield on the municipal

\footnotetext{
${ }^{31}$ The income on most municipal bonds is tax-exempt. This special tax treatment of municipal bonds means that the average yield of municipal bonds is normally lower than that of Treasury, corporate and agency bonds with the same maturity, because "short-maturity municipal yields are equal to the Treasury yield multiplied by one minus the income tax rate, and the ratio between municipal and Treasury yields decreases with maturity." (Ang et al., 2010, p. 566).
} 
yield became much stronger after the break in June 1999, i.e. in the short term the municipal bond yield became more dependent on the Treasury yield in the post-break period.

The findings for the municipal bond MCIs are similar to those reported previously. In the first 'conundrum' period month the decrease in the 10-year Treasury yields mostly explains why the municipal bond yield has decreased, whereas afterwards investor demand (up to -19bp impact) together with a decrease in the interest rate volatility (up to -13bp impact) are the major depressing factors. A puzzling result is the slightly negative MCI of the DOW Jones Index and the PCE deflator. This may be explained by the fact that according to the model a change in these variables only has a short term impact on the yield (i.e. although the Dow Jones Index and the PCE deflator increase in the long run, their monthly change was not mainly positive). The increase in the short term interest rate was therefore the only counteracting force against the downward pressure on the yield.

\section{[Insert Figure 7 here]}

Our main finding is that investor demand from foreign official and foreign and domestic private sources is crucial to explain the bond yield 'conundrum' in all traditional AAA rated US long term bond markets. The increase in foreign official demand seemingly not only had a direct negative impact on the Treasury (and agency) yield but also an indirect impact on non-Treasury yields (especially between mid-2004 and the end of 2005): Figure 3 shows that most of the downward pressure on the 10-year Treasury yield stemmed from the increasing demand of foreign official investors. A lower Treasury yield, in turn, had a negative impact on the other yields (as reported above). Therefore, the increase in foreign official demand for 10-year Treasury bonds also, indirectly, lowered the yield of other bonds via its negative impact on the 
Treasury yield. A second interesting finding is that the 10-year Treasury yield indeed can be seen as a benchmark for other long term bond yields. This is especially true for the agency bond yield.

\section{Investor demand and the subprime crisis}

The US ‘bond yield conundrum' has generated much discussion regarding its magnitude and the factors behind it for good reason. As Wu (2008) has argued: "The correct understanding and quantification of the conundrum have direct implications for monetary policy..." (p. 2). While we certainly agree with this argument we also believe that a 'correct understanding and quantification of the conundrum' as manifested in all of the major US bond markets - and not merely in the market for Treasuries - can help to shed more light on the root causes of the recent financial crisis and, in so doing, help guide policy makers in their attempts to prevent a similar crisis on this scale in the future. The logic behind this position is straightforward.

The securities at the epicenter of the financial crisis that broke out in the summer of 2007 were CDOs. The estimated amount of CDOs in 2002 was about $\$ 1 / 4$ trillion and yet by the time of the crisis that figure had multiplied twelvefold to about $\$ 3$ trillion with the bulk of it comprising of AAA rated tranches (Blundell-Wignall, 2007) ${ }^{32}$. One of the unresolved questions regarding this rapid increase in the $\mathrm{CDO}$ market concerns the precise role played by investor demand. Did this demand play a merely passive role? Yields in the other debt securities markets were unusually low in the immediate pre-crisis period and so investors would have been happy to accept the higher yielding CDOs, but was the quest for fees and commissions on the part of the banks and their associates the more important driving force behind the rapid acceleration in

\footnotetext{
32 The rapid growth of the securitisation market meant that the subprime mortgage market also had to grow strongly, which lead to a dramatic deterioration of the loan quality and performance and subsequently to the collapse of the market (see e.g. Demyanyk and Van Hemert, 2011).
} 
CDO production? Or did investor demand play a more active role in the growth of the CDO market? The US financial institutions may have profited handsomely from the creation and distribution of CDOs but were these institutions also under enormous external pressure to do all of this in order to make up for the shortfall in the supply of other US safe assets?

If the answer to the above question is that investor demand did indeed play a secondary role in CDO growth then it is entirely correct for policy makers to concentrate their efforts on rectifying the various institutional and regulatory errors and failures that allowed the US banking system to create the toxic debt securities on so large a scale in such a short time span. However, this policy approach would not on its own prevent future financial crises if it turned out that the demand for extra safe assets was in fact the more important driver behind CDO growth, as recent research from Caballero and Krishnamurthy (2009) suggests. From this alternative, demand-side, perspective on $\mathrm{CDO}$ growth "the core policy problem to deal with is how to bridge the safe asset gap without over-exposing the financial sector to systemic risk." (Caballero, 2010, p. 6). Thus, imposing various new rules and restrictions on the US financial sector's ability to create debt assets will not only “...not help to deal with the structural problem of excess safe-asset demand.” but will also have the opposite effect of worsening the safe asset gap, the potential “...cost of this policy distortion [being] stronger headwinds for the recovery and the risk that the same pattern of systemically-vulnerable safe-asset creation may migrate to somewhere else in the world that is even less prepared to absorb the systemic risk." (ibid, p. 6-7).

Caballero's take on the major policy lessons of the subprime crisis remains a minority one and a possible reason for this is that to date there has been no comprehensive attempt at econometrically testing the strength of foreign and domestic demand for US safe assets in the pre-crisis era. The crux of the matter is that CDOs are essentially 'second-floor' debt securities, 
securities backed by securities. Thus, for the demand-pull version of the CDO growth story to be really credible, it has to be convincingly demonstrated that the pressure of aggregate demand for safe stores of value was so great that the combined capacity of all the US 'ground floor' debt securities markets (those for corporate and municipal securities in addition to that for Treasuries) and of the US 'first floor' securities markets (those for agency and other asset backed securities) was simply not large enough to fully accommodate that pressure. We believe that the econometric results generated in this paper amount to such a demonstration insofar as they consistently point to significant and substantial downward demand pressure on all US bond yields in the pre-crisis period. This is especially true if one takes into account that the US long term non-Treasury yields were also reduced by the low 10-year Treasury yield, which, in turn, was negatively influenced by the increase in foreign official investor demand for Treasury bonds.

\section{Conclusion}

Our models fully explain the US 'bond yield conundrum' of 2004 to 2007 as found not only in relation to US Treasuries but also in relation to all of the other traditional AAA rated US debt securities, something that has not been achieved in the previous literature. We attribute this result to the incorporation of a broader set of variables than is usual in our models, this being made possible by the adoption of the ARDL approach, and to the allowance for evident structural change at the end of the 1990s (the latter confirming findings of previous authors). We find that long term non-Treasury yields are significantly influenced by the 10-year Treasury yield and that the latter is important to explain the low pre-crisis long term yields of the former (the 10-year Treasury yield lowered non-Treasury yields by up to 64bp in the 'conundrum' period). This is 
especially true for 10-year agency bonds that investors seemingly regarded as the closest substitute for 10-year Treasury bonds.

We furthermore find that, if one accounts for the negative indirect effect of foreign official investor demand on non-Treasury yields via their depressing effects on the Treasury yield, investor demand seemingly is the most prominent factor in explaining the unusually low long term US bond yields in the 'conundrum' period. The direct negative impact of foreign official investor demand was up to 60bp in absolute value in the case of the 10-year Treasury yield and up to $43 \mathrm{bp}$ in the case of the 10-year agency bond yield, whereas foreign and domestic private demand reduced the 10 -year agency bond yield by up to $29 \mathrm{bp}$ in absolute value, and the AAA rated long term corporate and municipal bond yields by up to $19 \mathrm{bp}$. This finding has substantial policy implications in that it provides support for the hitherto underexplored hypothesis that next to regulatory and market failures an excess safe asset demand on the part of investors was a chief force that drove the expansion of the US CDO market well beyond what was prudent. 


\section{Acknowledgements}

We are thankful to Moody's Analytics UK and Andreas Kalenteridis for providing us with data on the expected default frequency (EDF) of corporations. Furthermore, we would like to thank Engelbert Stockhammer, Gary van Vuuren, Matthew Greenwood-Nimmo and the participants at our presentation at the $61^{\text {st }}$ Congrès de l'Association Française de Science Economique (AFSE) for their helpful comments.

\section{References}

Ang, A., Bhansali, V., and Xing, Y., 2010. Taxes on Tax-Exempt Bonds. Journal of Finance $65,565-601$.

Bandholz, H., Clostermann, J., and Seitz, F., 2009. Explaining the US bond yield conundrum. Applied Financial Economics 19(7), 539-550.

Bernanke, B.S., Bertaut, C., Pounder DeMarco, L., and Kamin, S., 2011. International capital flows and the returns to safe assets in the United States: 2003-2007. Banque de France Financial Stability Review 15, 13-26.

Bernanke, B.S., Reinhart, V.R., and Sack, B.P., 2004. Monetary Policy Alternatives at the Zero Bound: An Empirical Assessment. Brookings Papers on Economic Activity 35(2), 1-100.

Bertaut, C., Pounder DeMarco, L., Kamin, S.B., and Tryon, R.W., 2011. ABS inflows to the United States and the global financial crisis. NBER Working Paper No. 17350.

Blundell-Wignall, A., 2007. Structured Products: Implications for Financial Markets. Financial Market Trends 93(2), 27-57.

Caballero, R.J., and Krishnamurthy, A., 2009. Global Imbalances and Financial Fragility. American Economic Review 99(2), 584-588.

Caballero, R.J., 2010. The "Other" Imbalance and the Financial Crisis. NBER Working Paper No. 15636. 
Craine, R., and Martin, V.L., 2009. The Interest Rate Conundrum. The B.E. Journal of Macroeconomics 9(1), 1-27.

De Boef, S., and Keele, L., 2008. Taking Time Seriously. American Journal of Political Science 52(1), 184-200.

Demyanyk, Y., and Van Hemert, O., 2011. Understanding the Subprime Mortgage Crisis. Review of Financial Studies 24(6), 1848-1880.

Diebold, F.X., Piazzesi, M., and Rudebusch, G.D., 2005. Modeling Bond Yields in Finance and Macroeconomics. American Economic Review 95(2), 415-420.

Dwyer, G.P., and Tkac, P., 2009. The financial crisis of 2008 in fixed-income markets. Journal of International Money and Finance 28(8), 1293-1316.

ECB, 2006. The Accumulation of Foreign Reserves. ECB Occasional Paper No. 43.

Eijffinger, S., Mahieu, R., and Raes, L., 2010. The Bond yield conundrum: alternative hypotheses and the state of the economy. EBC Discussion Paper No. 2010-30.

Greenspan, A., 2005. Testimony of Chairman Alan Greenspan: The economic outlook, June 9. Manuscript, Federal Reserve Board.

Greenwood, R., and Vayanos, D., 2010. Price Pressure in the Government Bond Market, American Economic Review 100(2), 585-590.

Gros, D., 2009. Global Imbalances and the Accumulation of Risk. CEPS Policy Brief No. 189.

Hansen, B.E., 1997. Approximate Asymptotic P Values for Structural-Change Tests. Journal of Business and Economic Statistics 15(1), 60-67.

Idier, J., Jardet, C., and De Loubens, A., 2007. Determinants of long term interest rates in the United States and the Euro area: a multivariate approach. Banque de France Working Paper No. 170.

Kim, D.H., 2007. Challenges in macro-finance modeling. BIS Working Paper No. 240.

Kozicki, S., and Sellon, G., 2005. Longer-Term Perspectives on the Yield Curve and Monetary Policy. Economic Review 31(4), 5-33.

Krishnamurthy, A., and Vissing-Jorgensen, A., 2007. The Demand for Treasury Debt. NBER Working Paper No. 12881.

Laubach, T., 2009. New Evidence on the Interest Rate Effects of Budget Deficits and Debt. Journal of the European Economic Association 7(4), 858-885. 
Lysandrou, P., 2009. The Root Cause of the Financial Crisis: A Demand-Side View. Financial Times Economists Forum, March 24.

Pesaran, M. H., and Shin, Y., 1995. An Autoregressive Distributed Lag Modeling Approach to Cointegration Analysis. University of Cambridge Working Paper No. 9514.

Pesaran, M.H., Shin, Y., and Smith, R.J., 2001. Bounds Testing Approaches to the Analysis of Level Relationships. Journal of Applied Econometrics 16(3), 289-326.

Rudebusch, G.D., 2010. Macro-Finance Models of Interest Rates and the Economy, The Manchester School 78(s1), 25-52.

Rudebusch, G.D., Swanson, E.T., and Wu, T., 2006. The Bond Yield "Conundrum" from a Macro-Finance Perspective. Monetary and Economic Studies 24(s1), 83-109.

Rudebusch, G.D., and Wu T., 2008. A Macro-Finance Model of the Term Structure, Monetary Policy and the Economy. Economic Journal 118(530), 906-926.

Sarno, L., Thornton, D.L., and Valente, G., 2007. The Empirical Failure of the Expectations Hypothesis of the Term Structure of Bond Yields. Journal of Financial and Quantitative Analysis 42(1), 81-100.

Shin, Y., Yu, B. and Greenwood-Nimmo, M.J., 2013. Modelling Asymmetric Cointegration and Dynamic Multipliers in a Nonlinear ARDL Framework. In William C. Horrace and Robin C. Sickles (Eds.), Festschrift in Honor of Peter Schmidt. New York (NY): Springer Science \& Business Media.

Stiglitz, J.E., and Greenwald, B., 2003. Towards a New Paradigm in Monetary Economics, Cambridge University Press, Cambridge.

Tang, H., and Xia, Y., 2007. An International Examination of Affine Term Structure Models and the Expectation Hypothesis. Journal of Financial and Quantitative Analysis 42(1), 4180 .

Thornton, D.L., 2007. The Unusual Behavior of the Federal Funds and 10-Year Treasury Rates: A Conundrum or Goodharts Law? Fed St. Louis Working Paper No. 2007-039C.

Trainer, E.M., 2006. Using Economic Indicators to Improve Investment Analysis, Wiley, Hoboken (N.J.).

Warnock, F.E., and Cacdac Warnock, V., 2009. International capital flows and U.S. interest rates. Journal of International Money and Finance 28, 903-919.

Wu, T., 2005. The Long Term Interest Rate Conundrum: Not Unraveled Yet?, Fed San Francisco Economic Letter No. 2005-08. 
Wu, T., 2008. Accounting For the Bond-Yield Conundrum. Fed Dallas Economic Letter No. $3(2)$.

Xiao, Y.J., and Xiao, Y., 2009. Adequacy of Bond Supply and Cost of Pension Benefits: A Financial Economics Perspective. SOA Working Paper. 


\section{Table 1}

Quandt-Andrews unknown breakpoint test results. ${ }^{a}$

\begin{tabular}{|lcccc|}
\hline & Treasury model & Agency model & Corporate model & Municipal model \\
\hline Max Likelihood Ratio F-statistic prob & 0.062 & 0.092 & 0.018 & 0.086 \\
Date & 1998.11 & 1999.08 & 1998.07 & 1999.06 \\
\hline
\end{tabular}

${ }^{a}$ This table shows the results of the Quandt-Andrews unknown breakpoint tests (35\% trimmed data, probabilities calculated using Hansen's (1997) method). The presented figures are F-statistic probabilities and the dates of the breakpoints. 


\section{Table 2}

Parsimonious model of the nominal 10-year Treasury yield. ${ }^{\mathrm{a}}$

\begin{tabular}{|c|c|c|c|c|c|c|c|}
\hline \multirow{3}{*}{$\begin{array}{c}\Delta(\text { FOROFFICIAL) } \\
\Delta(\text { FOROFFICIAL(-1)) }\end{array}$} & \multicolumn{2}{|c|}{ (i) without break } & \multicolumn{2}{|c|}{ (ii) with break } & \multirow{2}{*}{\multicolumn{3}{|c|}{$\begin{array}{c}\text { (iii) equilibrium long-run effects of (ii) } \\
\text { before the break }\end{array}$}} \\
\hline & $-0.2174 * * *$ & $(-6.44)$ & \multirow{2}{*}{$\begin{array}{l}-0.2155^{* * *} \\
-0.1325^{* * *}\end{array}$} & \multirow{2}{*}{$\begin{array}{l}(-6.81) \\
(-4.11)\end{array}$} & & & \\
\hline & $-0.1273^{* * *}$ & $(-3.58)$ & & & \multicolumn{3}{|c|}{$\begin{array}{lll}\text { FOROFFICIAL } & -0.0944^{* * *} & (-7.14)\end{array}$} \\
\hline$\Delta$ (EUR_DOL) & $0.3279^{* * *}$ & (3.42) & $0.7202^{* * *}$ & $(4.38)$ & FORPRIVATE & $-0.2396 * * *$ & $(-5.82$ \\
\hline \multicolumn{3}{|l|}{$\Delta(\text { EURDOL })^{s 11 / 98}$} & \multicolumn{2}{|c|}{$-0.5256 * * *(-2.98)$} & EURDOL & $0.4478^{* * *}$ & $(4.50)$ \\
\hline \multicolumn{2}{|c|}{$-0.2459 * * * \quad(-2.62)$} & $(-2.62)$ & $-0.1630^{*}$ & $(-1.78)$ & LOGISM & $3.3286^{* * *}$ & $(5.52)$ \\
\hline$\Delta($ LOGISM) & $0.9202^{* *}$ & $(2.31)$ & $1.0200 * * *$ & $(2.65)$ & PCE & $0.9426 * * *$ & $(3.72)$ \\
\hline$\Delta($ LOGISM(-1)) & $1.1464^{* * *}$ & $(3.17)$ & $1.6376^{* * *}$ & $(2.86)$ & DOW & $0.0005^{* * *}$ & $(5.56)$ \\
\hline \multicolumn{3}{|l|}{$\Delta(\text { LOGISM(-1) })^{\text {s11/98 }}$} & $-1.2539 *$ & $(-1.80)$ & MOVE & $0.0070^{* * *}$ & $(2.88)$ \\
\hline$\Delta($ LOGISM(-4)) & $1.0097^{* * *}$ & $(2.83)$ & \multicolumn{2}{|c|}{$0.8844^{* * *} \quad(2.66)$} & \multicolumn{3}{|c|}{ after the break } \\
\hline$\Delta(\mathrm{PCE})$ & $0.5404^{* * *}$ & $(2.72)$ & \multicolumn{2}{|c|}{$0.5403^{* * *} \quad(2.90)$} & \multicolumn{2}{|c|}{$\begin{array}{ll}\text { FOROFFICIAL } & -0.0944^{* * *}\end{array}$} & $(-7.14)$ \\
\hline$\Delta(\mathrm{PCE}(-9))$ & $-0.6486 * * *$ & $(-2.98)$ & $-0.6432 * * *$ & $(-3.12)$ & FORPRIVATE & 0.0038 & $(0.07)$ \\
\hline$\Delta(\mathrm{DOW})$ & $0.0001^{* *}$ & $(2.36)$ & $0.0001^{* *}$ & (3.14) & EURDOL & $0.1113^{* * *}$ & $(2.85)$ \\
\hline$\Delta(\operatorname{DOW}(-1))$ & $0.0001^{* *}$ & $(2.50)$ & & & LOGISM & $2.5283^{* * *}$ & $(3.61)$ \\
\hline YIELD(-1) & $-0.2835^{* * *}$ & $(-6.13)$ & $-0.3795 * * *$ & $(-6.63)$ & PCE & $0.9426^{* * *}$ & (3.72) \\
\hline FOROFFICIAL(-1) & $-0.0224 * * *$ & $(-3.46)$ & $-0.0358^{* * *}$ & $(-4.67)$ & DOW & $0.0005^{* * *}$ & $(5.56)$ \\
\hline FORPRIVATE(-1) & $-0.0252^{* *}$ & $(-2.07)$ & $-0.0909 * * *$ & $(-6.50)$ & MOVE & $0.0070^{* * *}$ & $(2.88)$ \\
\hline FORPRIVATE $(-1)^{511 / 98}$ & & & $0.0924^{* * *}$ & (3.62) & & & \\
\hline EURDOL(-1) & $0.0535^{* * *}$ & $(3.36)$ & $0.1700^{* * *}$ & (3.45) & misspecification & cointegratio & in tests \\
\hline EURDOL(-1) & & & $-0.1277^{* * *}$ & $(-2.73)$ & & (i) & (ii) \\
\hline LOGISM(-1) & $0.8877^{* * *}$ & (2.91) & $1.2634^{* * *}$ & (4.69) & BG(2) prob. & 0.16 & 0.24 \\
\hline LOGISM(-1) $)^{\text {s11/98 }}$ & & & $0.3038^{* *}$ & $(-2.29)$ & $\mathrm{BG}(12)$ prob. & 0.25 & 0.36 \\
\hline PCE $(-1)$ & $0.2431^{* *}$ & $(2.28)$ & $0.3578^{* * *}$ & (3.28) & Jarque-Bera prob. & 0.44 & 0.26 \\
\hline CPI10Y(-1) & $0.3855^{* *}$ & $(2.05)$ & & & $\operatorname{Arch}(1)$ prob. & 0.90 & 0.56 \\
\hline DOW(-1) & $0.0001^{* * *}$ & (3.53) & $0.0002 * * *$ & $(5.88)$ & Arch(12) prob. & 0.56 & 0.49 \\
\hline $\operatorname{MOVE}(-1)$ & $0.0021 * *$ & $(2.27)$ & $0.0027^{* * *}$ & (2.78) & White prob. & 0.34 & 0.61 \\
\hline adj. R-squared & 0.58 & & 0.64 & & Ramsey LR prob. & 0.87 & 0.15 \\
\hline Schwarz criterion & -0.47 & & -0.54 & & Wu-Hausm. prob. & 0.85 & 0.58 \\
\hline Sample: $1994: 02$ to 200 & 7:06 (161 ob & servation & & & Bounds test F-stat. & $6.44 * * *$ & $8.20^{* * *}$ \\
\hline & & & & & Bounds test t-stat. & $-6.13^{* * *}$ & $-6.63^{* * *}$ \\
\hline
\end{tabular}

${ }^{\text {a }}$ This table summarizes the results of our ARDL-model for the nominal 10 -year Treasury yield. Where $\Delta$ is the difference operator, the number of lags are indicated in parentheses as a suffix to a variable's name, $s^{11 / 98}$ indicates the shift component of a variable and the date of the structural break (i.e. after November 1998), YIELD is the 10year nominal Treasury yield, FOROFFICIAL are foreign official holdings as a ratio of total outstanding long-term Treasuries, FORPRIVATE are foreign private holdings as a ratio of total outstanding long-term Treasuries, EURDOL is the 3-month Eurodollar rate, LOGISM is the log of the ISM-Index, PCE is the actual PCE inflation rate, $C P I 10 Y$ are 10-year CPI inflation expectations, DOW is the value of the Dow Jones Index, and MOVE is the Merrill Lynch Option Volatility Estimate Index. Intercepts are not reported but are included in the models. In each column coefficients and t-statistics (in parenthesis) are reported. Probability values for all misspecification tests are reported in the section headed misspecification/cointegration tests, where BG(x) denotes the probability value of the BreuschGodfrey test for $\mathrm{x}$ order correlation and $\operatorname{Arch}(\mathrm{x})$ the probability value of the ARCH heteroskedasticity test with $\mathrm{x}$ lags. The 5\% critical values for the bounds cointegration test with unrestricted intercept and no trend are (i) $\mathrm{F}=3.39$, $\mathrm{t}=-4.72$, (ii) $\mathrm{F}=3.50, \mathrm{t}=-5.03$ [(i) $\mathrm{k}=8$, (ii) $\mathrm{k}=10(\mathrm{t}), \mathrm{k}=7(\mathrm{~F})]$ - see Pesaran et al. (2001). The significance of a coefficient or test statistic at the $1 \%, 5 \%$ and $10 \%$ level of significance is indicated by ***, ** and *, respectively. 


\section{Table 3}

Parsimonious model of the nominal long term yields of AAA-rated non-Treasury US securities. ${ }^{\text {a }}$

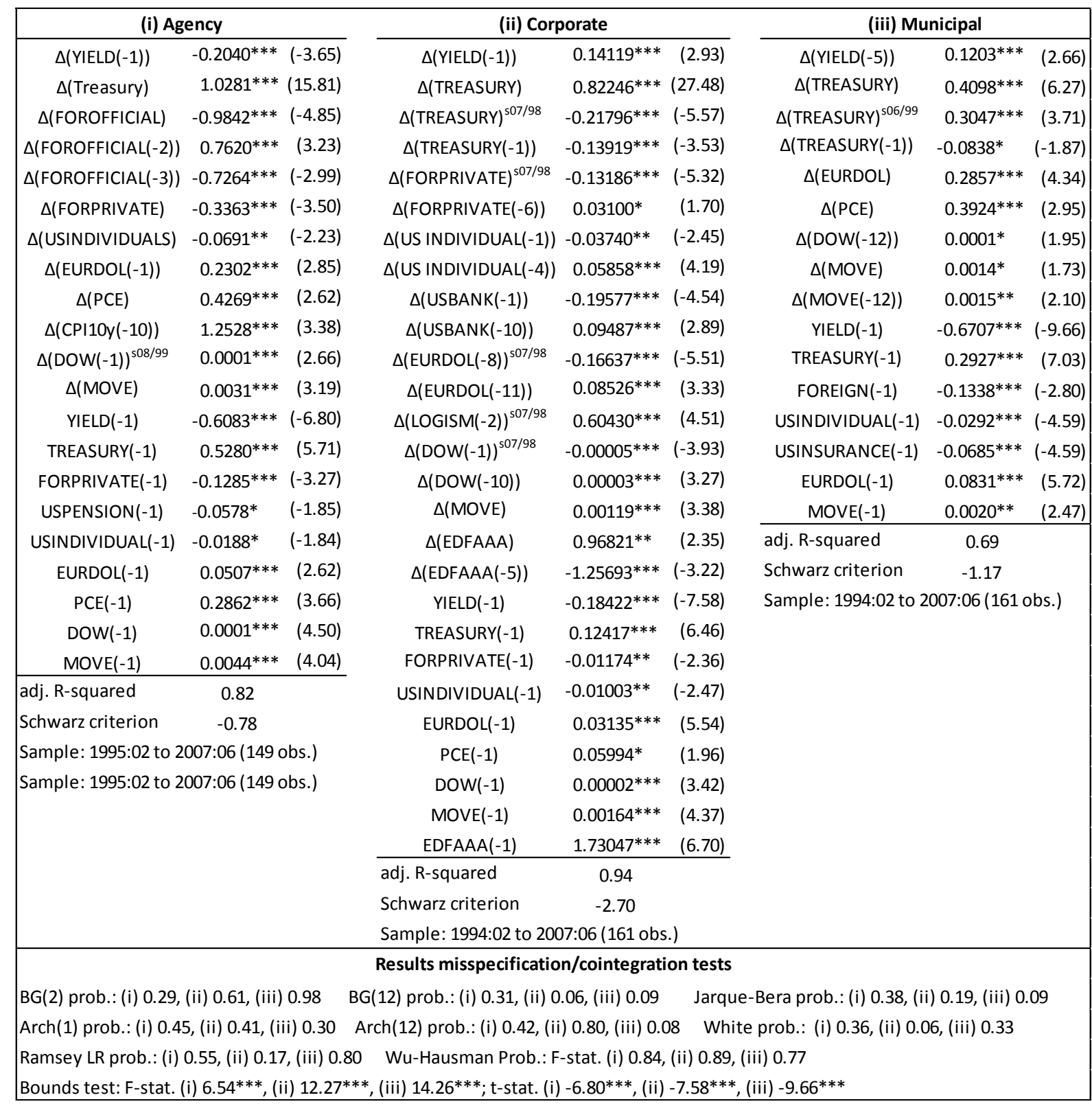

${ }^{a}$ This table summarizes the results of our ARDL-models for the nominal 10-year US agency, and AAA-rated corporate and municipal bond yields, respectively. The table notes are the same as in Table 2, with the following exceptions: $s^{x / x}$ indicates the shift component of a variable with the date of the structural break indicated by $x / x$ (i.e. after July 1998 , June 1999 and August 1999 respectively), YIELD is the nominal AAA-rated long-term yield of the respective bond class, FOROFFICIAL are foreign official holdings as a ratio of total outstanding bonds (i.e. the holdings ratio) of the respective bond class, FORPRIVATE is the foreign private holdings ratio of the respective bond class, FOREIGN is the foreign holdings ratio of municipal bonds, USBANK is the US banking institutions holdings ratio of the respective bond class, USINDIVIDUAL is the US individual holdings ratio of the respective bond class, USINSURANCE is the US insurance companies holdings ratio of municipal bonds, USPENSION is the US pension funds holdings ratio of agency bonds, and EDFAAA is Moody's expected default frequency for AAA-rated corporate bonds. The $5 \%$ critical values for a Bounds cointegration test with unresticted intercept and no trend are (i) $\mathrm{f}=3.30$, $\mathrm{t}=-4.88$, (ii) $\mathrm{f}=3.30, \mathrm{t}=-4.88$, (iii) $\mathrm{f}=3.50, \mathrm{t}=-4.57$ [(i) $\mathrm{k}=9$, (ii) $\mathrm{k}=9$, (iii) $\mathrm{k}=7$ ] - see Pesaran et al. (2001). 


\section{Table 4}

Equilibrium long run impacts on the nominal long term yields of AAA-rated non-Treasury US securities. ${ }^{\text {a }}$

\begin{tabular}{|c|c|c|c|c|c|c|}
\hline \multicolumn{3}{|c|}{ before the break } & \multicolumn{2}{|c|}{ before the break } & \multicolumn{2}{|c|}{ before the break } \\
\hline TREASURY & $0.8679 * * *$ & (15.62) & TREASURY & $0.6740^{* * *}(11.66)$ & TREASURY & $0.4364^{* * *}(12.12)$ \\
\hline FORPRIVATE & $-0.2112 * * *$ & $(-3.73)$ & FORPRIVATE & $-0.0637 * * * \quad(-2.66)$ & FOREIGN & $-0.1995 * * * \quad(-2.88)$ \\
\hline USPENSION & $-0.0951^{* *}$ & $(-2.11)$ & USINDIVIDUAL & $-0.0544 * * * \quad(-2.61)$ & USINDIVIDUAL & $-0.0436 * * * \quad(-5.33)$ \\
\hline USINDIVIDUAL & $-0.0308^{*}$ & $(-1.94)$ & EURDOL & $0.1702 * * * \quad(4.88)$ & USINSURANCE & $-0.1021 * * * \quad(-5.32)$ \\
\hline EURDOL & $0.0834 * * *$ & $(2.82)$ & PCE & $0.3254 * * \quad(2.14)$ & EURDOL & $0.1239 * * * \quad(6.55)$ \\
\hline PCE & $0.4704 * * *$ & (4.19) & DOW & $0.0001 * * * \quad(3.65)$ & MOVE & $0.0030 * *$ \\
\hline DOW & $0.0001 * * *$ & (4.54) & MOVE & $0.0089 * * * \quad(4.89)$ & & \\
\hline MOVE & $0.0072^{* * *}$ & $(4.10)$ & EDFAAA & $9.3936 * * * \quad(8.22)$ & & \\
\hline \multicolumn{3}{|c|}{ after the break } & \multicolumn{2}{|c|}{ after the break } & \multicolumn{2}{|c|}{ after the break } \\
\hline TREASURY & $0.8679 * * *$ & $(15.62)$ & TREASURY & $0.6740 * * *(11.66)$ & TREASURY & $0.4364^{* * *}(12.12)$ \\
\hline FORPRIVATE & $-0.2112 * * *$ & $(-3.73)$ & FORPRIVATE & $-0.0637 * * * \quad(-2.66)$ & FOREIGN & $-0.1995 * * *(-2.88)$ \\
\hline USPENSION & $-0.0951^{* *}$ & $(-2.11)$ & USINDIVIDUAL & $-0.0544 * * * \quad(-2.61)$ & USINDIVIDUAL & $-0.0436 * * * \quad(-5.33)$ \\
\hline USINDIVIDUAL & $-0.0308^{*}$ & $(-1.94)$ & EURDOL & $0.1702 * * * \quad(4.88)$ & USINSURANCE & $-0.1021 * * * \quad(-5.32)$ \\
\hline EURDOL & $0.0834 * * *$ & $(2.82)$ & PCE & $0.3254^{* *} \quad(2.14)$ & EURDOL & $0.1239 * * * \quad(6.55)$ \\
\hline PCE & $0.4704^{* * *}$ & (4.19) & DOW & $0.0001^{* * *} \quad(3.65)$ & MOVE & $0.0030^{* *}$ \\
\hline DOW & $0.0001^{* * *}$ & $(4.54)$ & MOVE & $0.0089 * * * \quad(4.89)$ & & \\
\hline MOVE & $0.0072 * * *$ & $(4.10)$ & EDFAAA & $9.3936 * * * \quad(8.22)$ & & \\
\hline
\end{tabular}

${ }^{a}$ This table summarizes the equilibrium results of our ARDL-models for the nominal 10-year US agency, and AAArated corporate and municipal bond yields, respectively. The table notes are the same as in Table 2 and Table 3. 


\section{Long and short term interest rates in the US (in \%)}

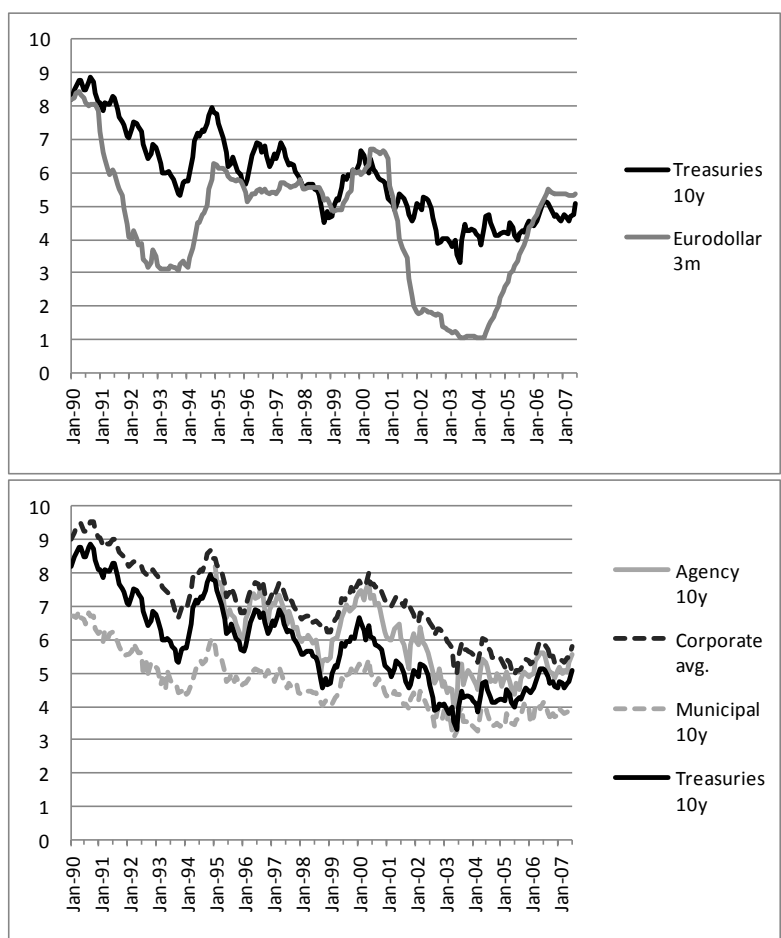

Fig. 1. The top plot compares the 3-month Eurodollar rate with the 10-year Treasury yield. The bottom plot demonstrates the downward movement of traditional long-term bond yields in the US (Sources: Bloomberg, 2010, FR Statistical Release H.15, 2010). 


\section{Foreign official holdings (US\$ bn)}

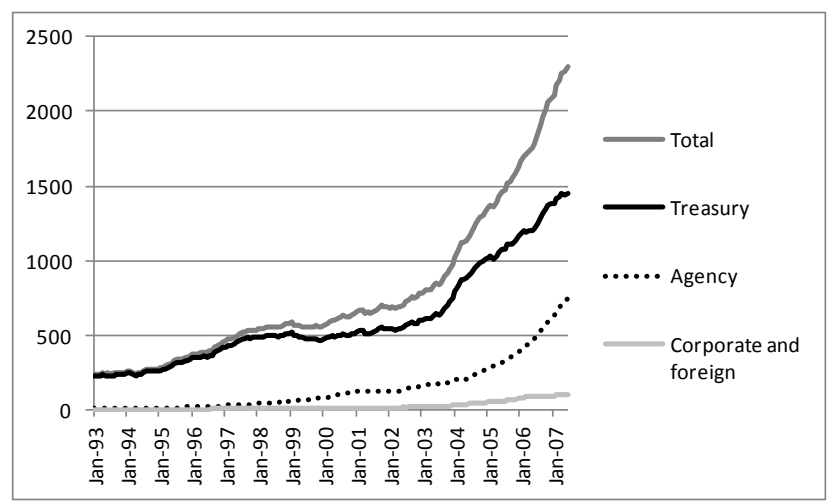

Foreign private holdings (US\$ bn)

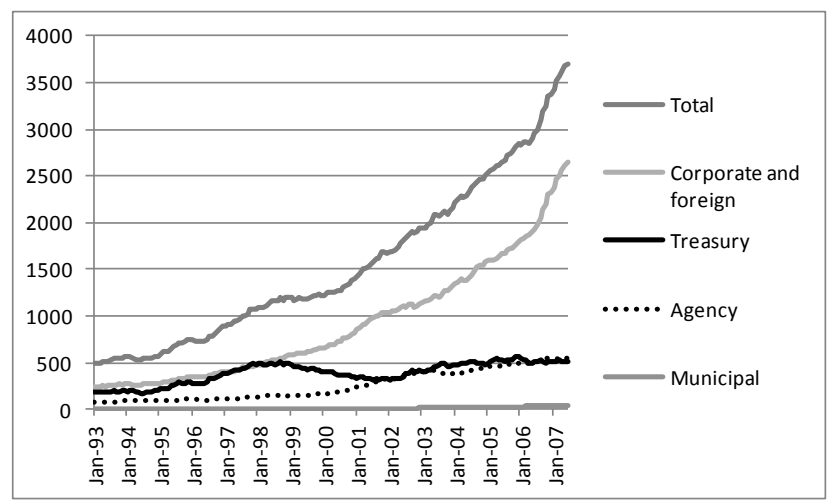

US private investor holdings (US\$ bn)

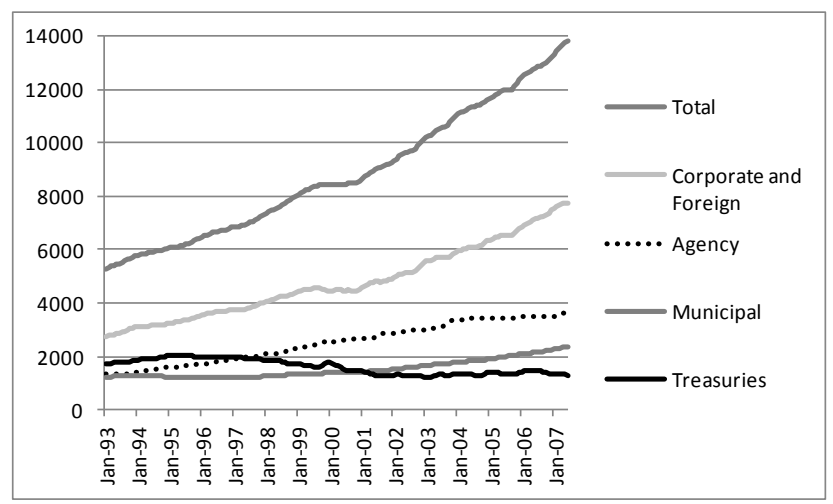

Fig. 2. US bond holdings from foreign and private domestic investors. The plots show the US bond holdings of foreign governments (top), foreign private investors (middle) and domestic private investors (bottom), respectively (Sources: FR Statistical Release Z.1, 2010, Treasury International Capital System, 2010). 


\section{Variables' MCIs for the nominal 10-year Treasury yield}
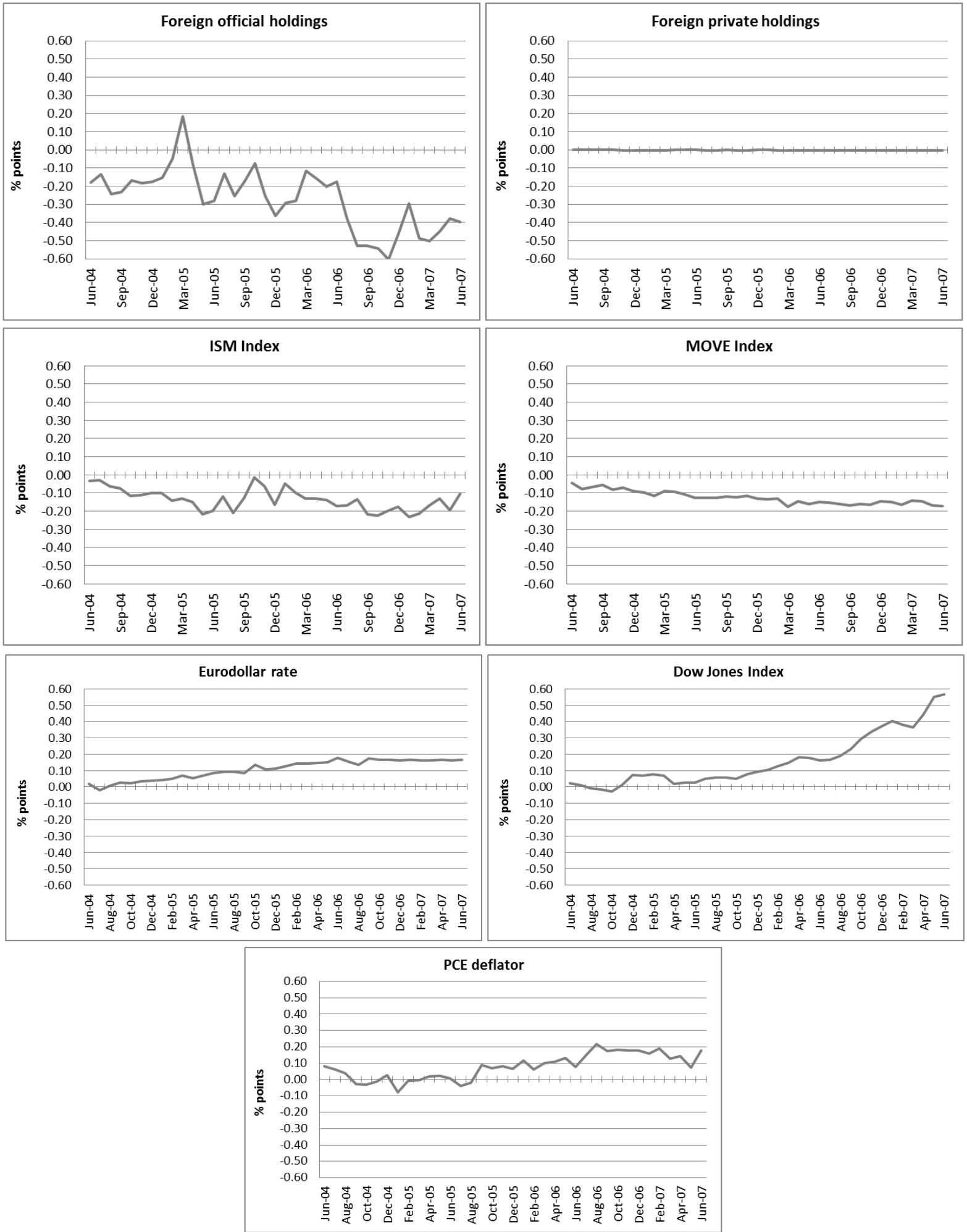

Fig. 3. These plots show the marginal cumulative impact of the demand variables on the nominal 10-year Treasury yield for each month during the conundrum period, according to the results of our Treasury yield model (see Table 2, column 2). 


\section{Yield residuals}
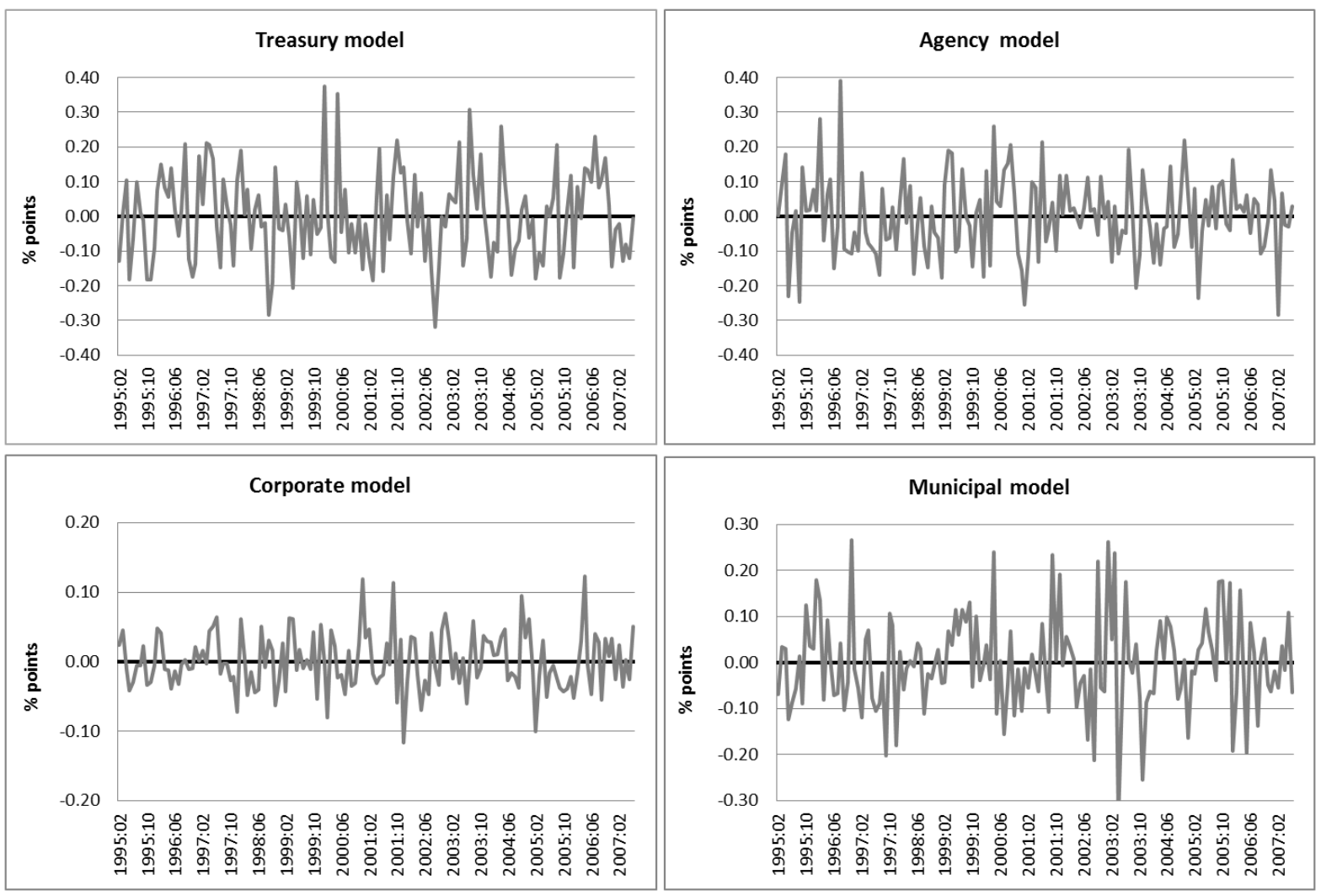

Fig. 4. These plots show how well the implied yield values of the respective models fit the respective long-term bond yields. 


\section{Variables' MCIs for the nominal 10-year agency bond yield}
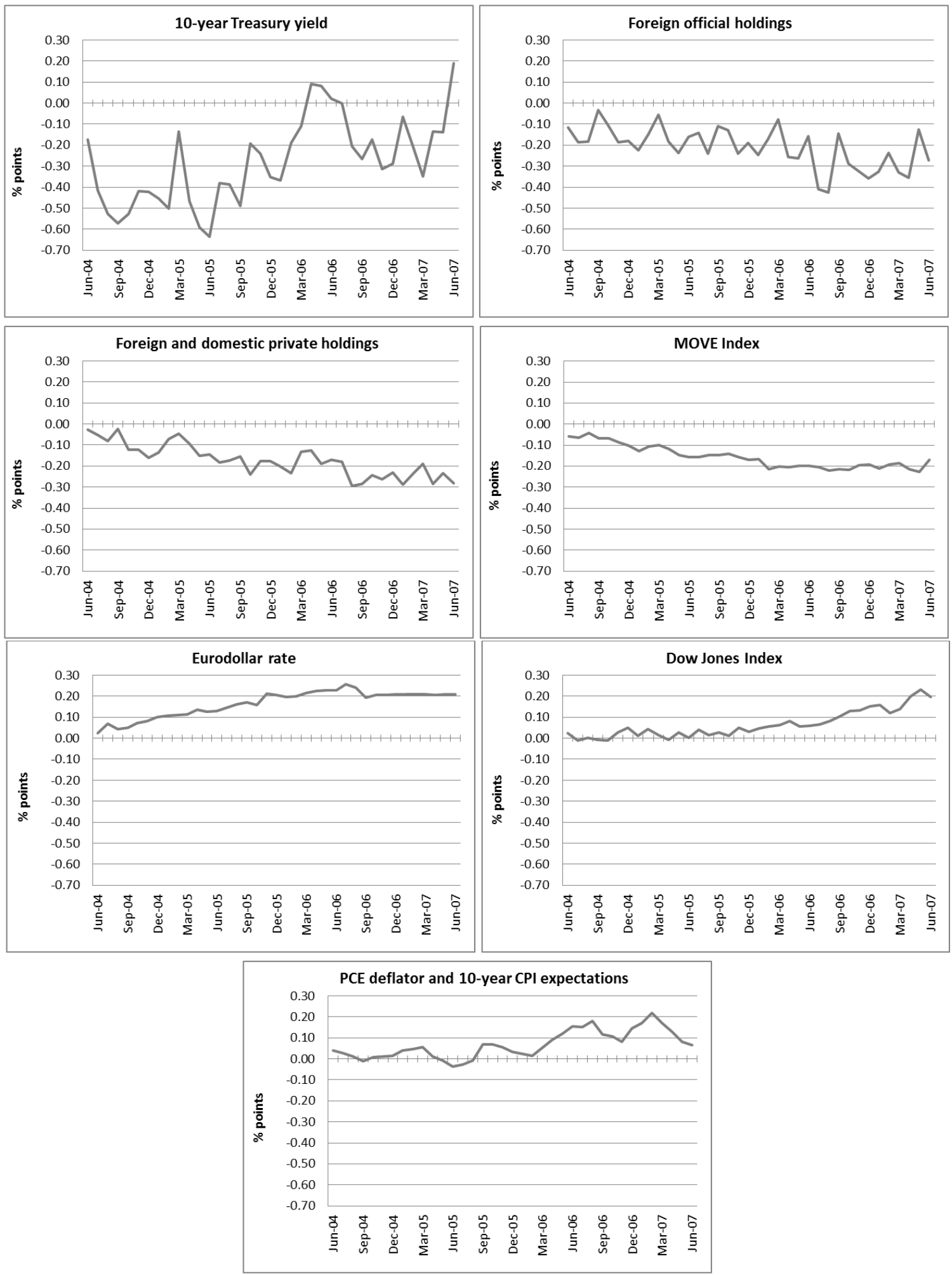

Fig. 5. These plots show the marginal cumulative impact of each variable on the nominal 10 -year agency bond yield for each month during the conundrum period, according to the results of our agency yield model (see Table 3, column 1). 


\section{Variables' MCIs for the nominal AAA-rated corporate bond yield}
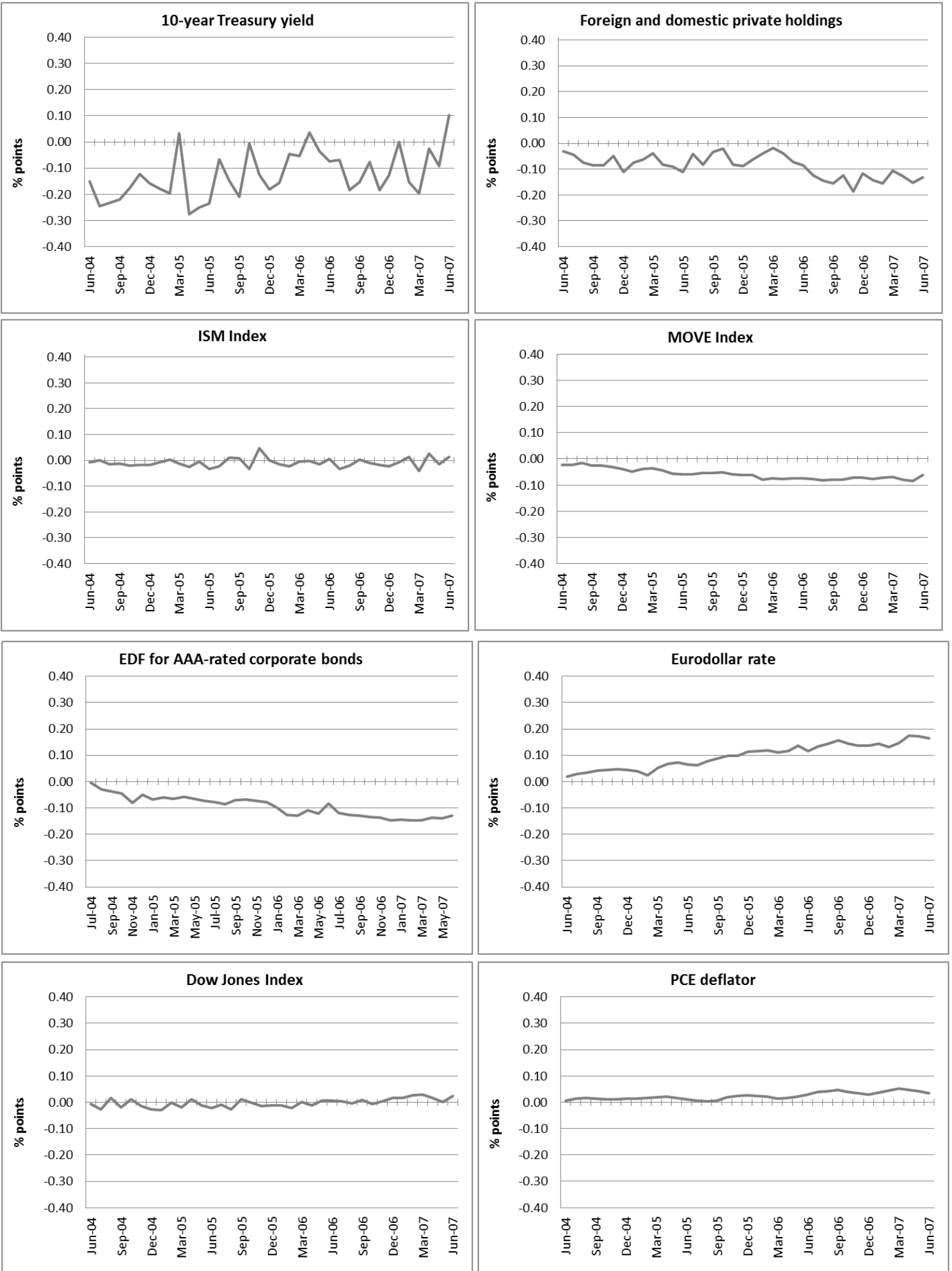

Fig. 6. These plots show the marginal cumulative impact of each variable on the nominal average AAA-rated corporate bond yield for each month during the conundrum period, according to the results of our corporate yield model (see Table 3, column 2). 


\section{Variables' MCIs for the nominal AAA-rated municipal bond yield}
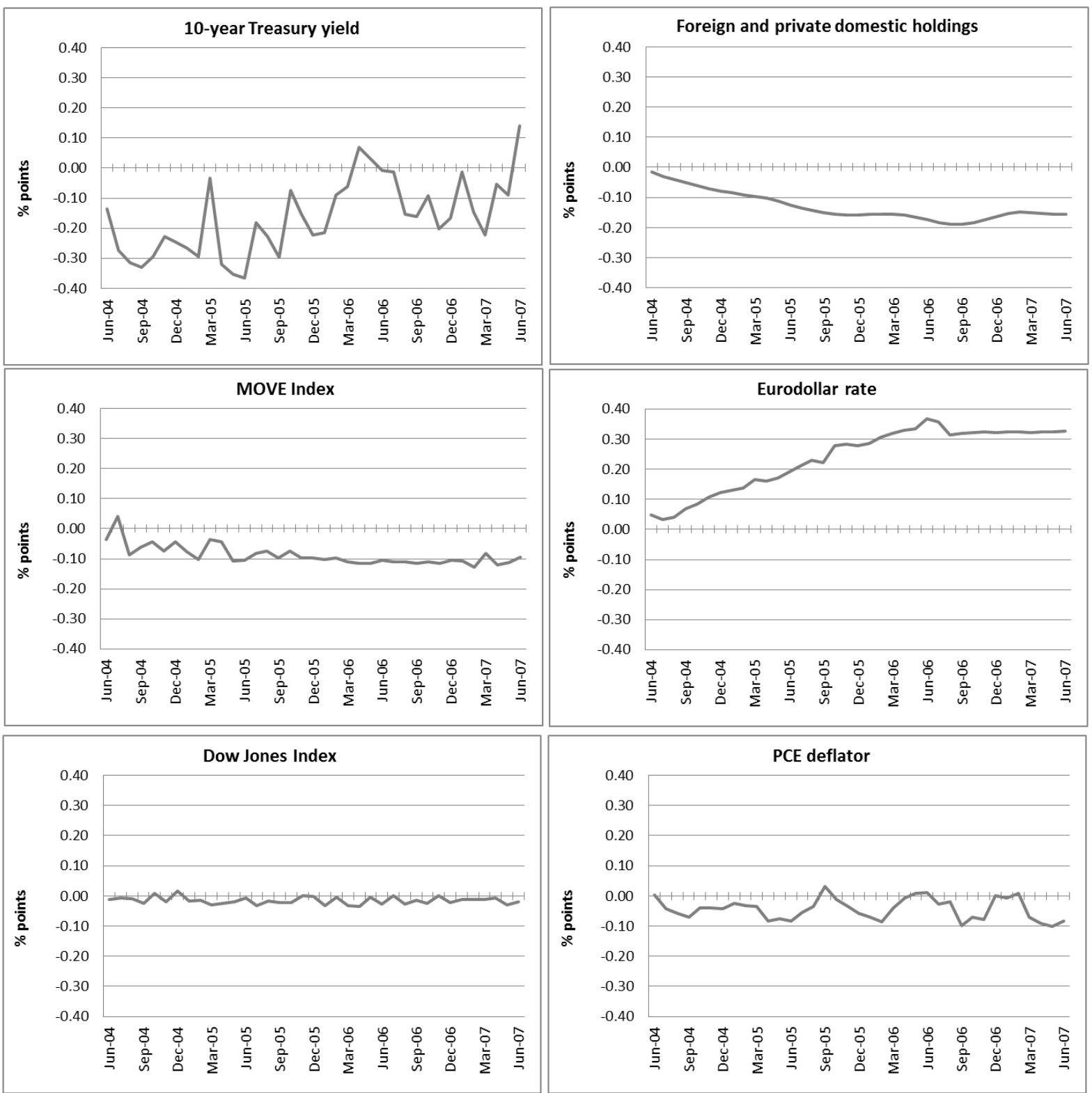

Fig. 7. These plots show the marginal cumulative impact of each variable on the nominal 10-year municipal bond yield for each month during the conundrum period, according to the results of our municipal yield model (see Table 3, column 3). 